Andrews University

Digital Commons @ Andrews University

\title{
Teacher Perceptions Of The Implementation Of The Common Core State Standards In The Schools Of The Florida Conference Of Seventh-Day Adventists: A Qualitative Case Study
}

Rose J. Thomas

Andrews University, roset@andrews.edu

Follow this and additional works at: https://digitalcommons.andrews.edu/dissertations

Part of the Education Commons

\footnotetext{
Recommended Citation

Thomas, Rose J., "Teacher Perceptions Of The Implementation Of The Common Core State Standards In The Schools Of The Florida Conference Of Seventh-Day Adventists: A Qualitative Case Study" (2017). Dissertations. 1642.

https://digitalcommons.andrews.edu/dissertations/1642

https://dx.doi.org/10.32597/dissertations/1642
}

This Dissertation is brought to you for free and open access by the Graduate Research at Digital Commons @ Andrews University. It has been accepted for inclusion in Dissertations by an authorized administrator of Digital Commons@ Andrews University. For more information, please contact repository@andrews.edu. 


\section{ABSTRACT}

\section{TEACHER PERCEPTIONS OF THE IMPLEMENTATION OF THE COMMON CORE STATE STANDARDS IN THE SCHOOLS OF THE FLORIDA CONFERENCE OF SEVENTH-DAY ADVENTISTS: A QUALITATIVE CASE STUDY}

\section{by}

Rose J. Thomas

Chair: Larry D. Burton 


\title{
ABSTRACT OF GRADUATE STUDENT RESEARCH
}

Dissertation

\author{
Andrews University \\ School of Education
}

\section{Title: TEACHER PERCEPTIONS OF THE IMPLEMENTATION OF THE COMMON CORE STATE STANDARDS IN THE SCHOOLS OF THE FLORIDA CONFERENCE OF SEVENTH-DAY ADVENTISTS: A QUALITATIVE CASE STUDY}

Name of researcher: Rose J. Thomas

Name and degree of faculty chair: Larry D. Burton, Ph.D.

Date completed: July 2017

Problem

This qualitative case study focused on educators who teach in the Florida Conference of Seventh-day Adventists and their perceptions regarding the adequacy of the Professional Development to support the implementation of the CCSS; how they are implementing the CCSS in the classroom in terms of planning, teaching, and assessing; and their perceptions regarding the impact of the CCSS on student learning.

\section{Method}

The study included six participants who taught in six different schools from the various regions where the Florida Conference schools are located. The participants varied 
in age, ethnicity, number of years in the classroom, and the size of their schools as indicated by the number of teachers at the school. In-depth interviews were conducted and two in-school visitations and classroom observations allowed for collections of field data.

\section{Results}

Data analysis of the interviews and classroom observations resulted in multiple codes or categories of perceptions. The study revealed that participants took part in a variety of professional learning but they did not receive adequate or formal training to support the implementation of the CCSS nor did they receive adequate planning to teach the Mathematics in the context of the shifts of the CCSS. However, once participants received introductory training from the conference, they continued with their own study and research about the CCSS which contributed to their having a positive impact on their teaching and student learning.

\section{Conclusions}

An investigation of the heart of the various categories yielded three themes: An array of learning- experiences in a variety of learning opportunities; a call for specificity in learning - the need for coherence between training and the CCSS adoption; and a drive for effectiveness in learning and teaching- to ensure teachers and learners success. 
Andrews University

School of Education

\title{
TEACHER PERCEPTIONS OF THE IMPLEMENTATION OF THE COMMON CORE STATE STANDARDS IN THE SCHOOLS OF THE FLORIDA CONFERENCE OF SEVENTH-DAY ADVENTISTS: A QUALITATIVE CASE STUDY
}

\author{
A Dissertation \\ Presented in Partial Fulfillment \\ of the Requirements for the Degree \\ Doctor of Philosophy
}

by

Rose J. Thomas

July 2017 
CCopyright by Rose J. Thomas 2017

All Rights Reserved 


\title{
TEACHER PERCEPTIONS OF THE IMPLEMENTATION OF THE COMMON CORE STATE STANDARDS IN THE SCHOOLS OF THE FLORIDA CONFERENCE OF SEVENTH-DAY ADVENTISTS: A QUALITATIVE CASE STUDY
}

\author{
A dissertation \\ presented in partial fulfillment \\ of the requirements for the degree \\ Doctor of Philosophy
}

by

Rose J. Thomas

APPROVAL BY THE COMMITTEE

Chair: Larry D. Burton

Dean, School of Education

Robson Marinho

Member: Sandra F. Doran

Member: Anneris Coria- Navia

External: Ruth Horton

Date approved 


\section{Dedication}

To my children, Samuel Joseph and Crystal Rose:

I have hoped to be an example for you two

but amazingly, I've been looking up to

you more and more each day. Your

intellect, compassion, and humor

inspire me! 


\section{TABLE OF CONTENTS}

LIST OF ABBREVIATIONS .................................................................. viii

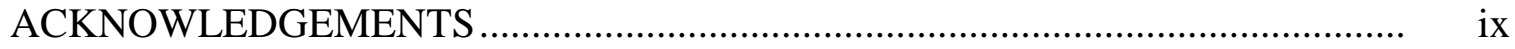

\section{Chapter}

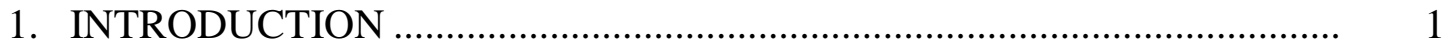

Rationale ...................................................................................... 2

Statement of the Problem...................................................................... 3

Purpose of the Study ........................................................................ 4

Philosophy, Research, and Observation................................................ 4

Research Questions ..................................................................... 5

Delimitations: Bounding the Case ...................................................... 6

Description of Terms ................................................................. 6

Significance of the Study ................................................................... 7

Organization of the Study ............................................................... 8

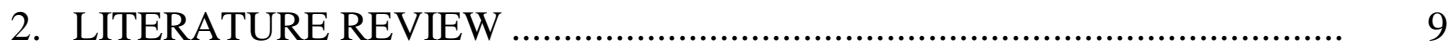

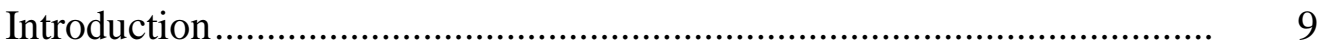

The Development of the CCSS ...................................................... 9

The CCSS and Prior Standards ........................................................... 11

Major Shifts in English Language Arts ....................................... 11

Major Shifts in Mathematics...................................................... 13

Perspectives on the CCSS ................................................................ 14

The Proponents of the CCSS .......................................................... 14

Common Response to a Common Concern ........................................ 14

Negative Views of the CCSS ....................................................... 15

Political Contribution to Negative Views of the CCSS .................... 17

Florida's Response to the CCSS and Race-to-the-Top Grants ........... 20

Importance of Professional Development............................................. 21

Misunderstanding of Ownership ......................................................... 23

Framework for Teacher Support ....................................................... 25

Principles of Change ................................................................. 25

Fullan's Steps to Change ............................................................. 30

Planning for Understanding and Backward Design......................... 31

Culture, Communication, and Cooperation in Change ...................... 33 
Change and Professional Development ………………......................... 37

Whole Faculty Study Group ............................................................ 42

Fullan's Change Process and the Florida Conference Adoption of the CCSS.......................................................................... 43

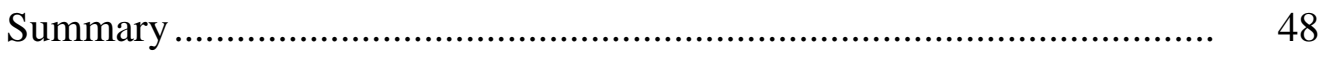

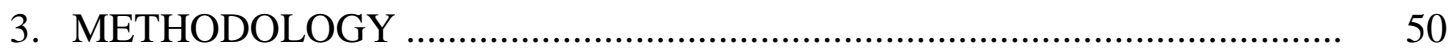

Study Focus ................................................................................ 50

Participants.............................................................................. 50

Population ……................................................................ 50

Criteria for Participation .............................................................. 53

Procedures in Data Collection ........................................................ 53

Invitation and Responses ........................................................ 54

The Second Drawing................................................................. 55

Sample Size......................................................................... 57

Data Sources ............................................................................. 5

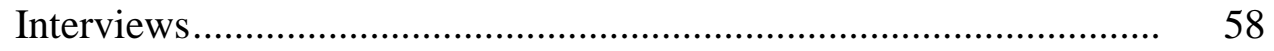

School and Classroom Observation ..................................................... 63

Documents and Artifacts............................................................... 64

Strategies for Validating Findings ……………………........................ 65

Researcher as Instrument ............................................................ 65

Researcher as Instrument: Benefits.............................................. 65

Researcher as Instrument: Disadvantages..................................... 66

Reflexivity........................................................................... 66

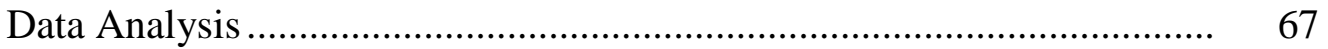

General Approach to Analysis ......................................................... 67

Ensuring High Quality Results ............................................................ $\quad 69$

Threats to Credibility of Results ....................................................... 69

Strengthening Credibility with Triangulation..................................... $\quad 70$

Ethical Conduct of Research.............................................................. 71

Protecting Against Personal Bias...................................................... 72

Protecting Human Subjects.............................................................. 73

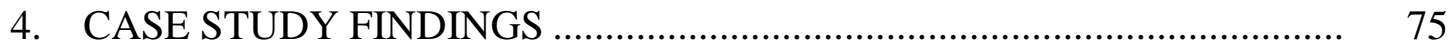

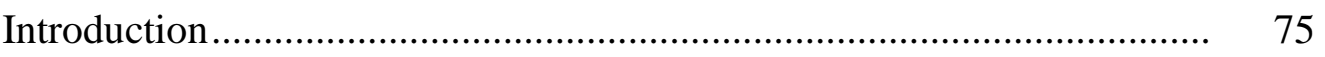

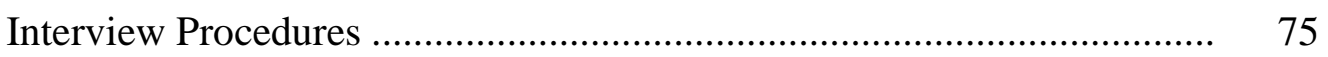

The Coding Process ………………………………………………..... 76

Study Findings .................................................................................... 77

Adequacy of Professional Development for

Implementation ........................................................................ 77

Perceptions of Adequate Preparation .................................................. 77

Adequate Preparation ..................................................................... 77

Inadequate Preparation ............................................................... 78

Inadequate Background in Mathematics.............................................. 78 
Inadequate Initial Training .......................................................... 80

No Formal Training .................................................................... 80

Planning, Teaching, and Assessing in the Age of CCSS .......................... 81

Using the Standards in Planning ...................................................... 81

Using the Standards in Teaching .................................................... 82

Using the Standards in Assessing ...................................................... 83

Perceptions of CCSS Impact on Student Learning ................................... 84

Positive Impact of the CCSS........................................................... 84

Negative Impact of the CCSS .......................................................... 86

Negative Impact on Students .................................................... 86

Negative Impact on Parents ........................................................ 86

Classroom Observations ...................................................................... 87

Observation of Instruction: ELA in a Florida Conference

Middle School...................................................................... 87

Observation of Instruction: Mathematics in a Florida

Conference Middle School ........................................................ 88

Classroom Observation and the Eight Principles of Teaching

Mathematics ........................................................................... 91

Principles A .......................................................................... 92

Principles B .................................................................... 93

Principles C ...................................................................... 93

Overarching Themes ......................................................................... 93

An Array of Learning................................................................... 94

A Call for Specificity in Learning ..................................................... 95

A Desire for Effectiveness in Learning and Teaching........................ 96

5. SUMMARY, DISCUSSION, \& CONCLUSIONS ………………………...... 98

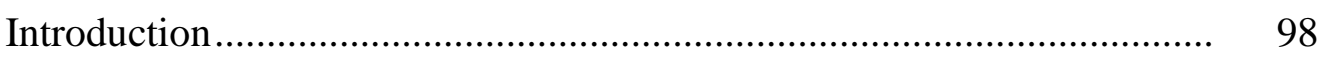

Review of CCSS Related Literature .................................................... 99

Educational Shifts in CCSS for ELA and Mathematics ..................... 99

Concerns Regarding the CCSS ...................................................... 100

Professional Development .................................................................. 100

Professional Development in Time of Change .................................... 100

Fullan's Three Steps to Change ......................................................... 101

Purposefulness and Professional Development ................................. 101

Productivity and Professional Development ........................................ 102

Personalization and Professional Development................................... 103

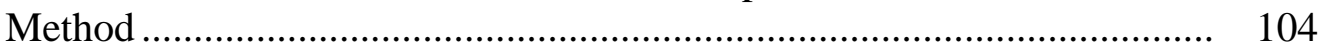

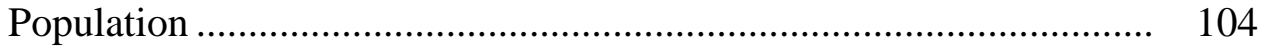

Criteria for Participation ................................................................ 104

Participant Selection …………………....................................... 105

Data Sources .................................................................................. 106

Data Analysis ................................................................................... 106

Interview Coding Process .............................................................. 106

Classroom Observation Coding ........................................................ 107 
Insuring High Quality Results ...................................................... 107

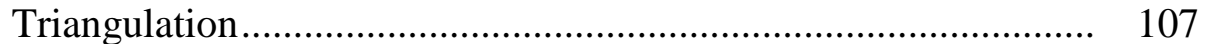

Reader's Feedback ……......................................................... 108

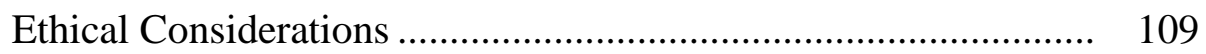

Findings and Discussion ................................................................... 109

An Array of Learning..................................................................... 109

A Call for Specificity in Learning ………......................................... 110

A Drive for Effectiveness in Learning and Teaching ......................... 112

Conclusions.............................................................................. 115

Implications for Practice .................................................................. 116

Recommendations for Future Research .............................................. 120

Limitations of the Study .......................................... 121

Closing Thought............................................................................ 121

\section{APPENDIX}

A. REQUEST FOR PERMISSION ……………………............................. 123

B. FLORIDA CONFERENCE PERMISSION TO CONDUCT RESEARCH.... 126

C. EMAIL TO FLORIDA CONFERENCE TEACHERS ................................... 128

D. TEACHER CONSENT FORM ……............................................................ 130

REFERENCE LIST ……………………………….................................. 132

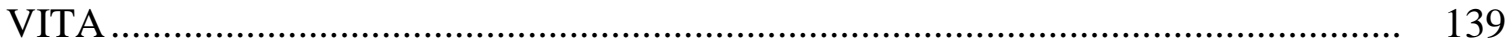




\section{LIST OF ABBREVIATIONS}

4MAT Meaning, adaptation, thinking (McCarthy's model for curriculum development). Provides support to the 4 major learning styles.

CCSS Common Core state standards, Common Core standards, state standards, and standards

CCSSO Council of Chief State School Officers

DC District of Columbia

ELA English Language Arts

ERIC Educational Resources Information Center

FLEC Forest Lake Education Center

NAD North American Division

NCLB No Child Left Behind

NGA National Governors Association

SPI Study participant intermediate (teacher of Grades 6-8)

SPP Study participant primary (teacher of Grades K-5) 


\section{ACKNOWLEDGEMENTS}

Many people have carried me along the way to make this dissertation possible. I thank:

My dissertation committee: Dr. Burton, Dr. Doran, and Dr. Navia for their support, kindness, and guidance throughout this process.

The six participants in the study: This would not have been possible without your generosity. Thank you for sharing your time and your thoughts.

My Florida Conference: Mr. Runnels, Dr. Doran, Ms. Rodriguez, Mrs. Thieme, \& Mr. Carazzana for their care and confidence and for giving me wings to soar as an educator.

My colleagues at the Forest Lake Education Center: Thank you for believing in me. You make me want to be better each day.

The three people who have shown excellence in customer service during my time at the university: Anna Piskozub, John Nay, and Qaisar Ayaz. I want to serve as you do.

The great group of professionals who served as editors and formatters for my dissertation: Josephine Katenga, Cheryl Logan, and Giny Lonser.

Mom: Thank you for making learning the most important thing in my life. As a child, you dreamed for me what no one did for you. You gave birth to the first literate generation and your passion for education allowed me to read books you'll never read and to write words you'll never decipher. You are the most visionary, brilliant, and insightful person I know. This dissertation is your hope and dream, your efforts and sacrifices for me.

My husband, Walden: Thanks for believing in me all these years. You see only the best in me and your support and love have carried me through these many years. This is for us.

My children, Samuel and Crystal: I love you both so very much. You are the very best parts of me. Thank you for cheering for me - always. supporter.

My sister, Nathalie: Thank you for your endless support and for being my best friend and

My immediate family - Walden, Nathalie, Samuel, Crystal, and Gina: You are my shelter. You are the rocks that anchor me against the storms of fear, tragedy, and despair. I could not have done this without you.

During the course of my doctoral program and especially during the dissertation process, I suffered four major losses. Deep in the pit of despair, three voices dragged me out and breathed courage into my heart:

My sister, Nancy, who placed me on a reporting schedule lest I tried to give up.

My best friend, Katia, who cheered me on and never stopped encouraging me.

My best friend, Tammy, who loved me through it all and when I could not go on, she simply said: “Just write!” I did. Painfully. Slowly. Not always eloquently. But I did.

And to my God who continues to paint the most beautiful pictures out of the ashes of my life. This is one of the sweetest portraits of courage, faith, and mercy. Thank you, Lord. 


\section{CHAPTER 1}

\section{INTRODUCTION}

School is the garden where the future grows. It is conceivable that it is often the ground for reformation, information, and change (O’Neill, 2000). Throughout history, education has undergone various changes. One such change is the most current adoption of the Common Core state standards (CCSS). After the initial preparation and background work were completed, these CCSS were introduced to the American nation in the year 2010 for the purpose of providing common English Language Arts (ELA) and Mathematics standards that states can adopt to form the basis for educating America's students (Gardner \& Powell, 2013).

The CCSS are marked by various educational shifts in ELA and Mathematics which will be covered in detail in Chapter 2 as part of the literature review. In ELA, the standards call for:

1. Regular practice with complex text and academic language

2. Reading, writing, and speaking grounded in evidence from texts - literary and informational

3. Building knowledge through content-rich nonfiction (Greene, 2012; National Governors Association [NGA] \& Council of Chief State School Officers [CCSSO], 2010).

The standards for Mathematics call for: 
1. Greater focus on fewer topics at each grade level

2. Mathematics coherence which provides for continuity of learning from one grade to the next level

3. Rigor in Mathematics for students to develop deep and true command of the concepts taught in each level (Greene, 2012; NGA \& CCSSO, 2010).

The Seventh-day Adventist educational system is organized from top down by the North American Division (NAD) Education Department, which is divided into nine unions among them the Southern Union, which comprises of seven conferences: Carolina, Florida, Georgia-Cumberland, Gulf State, and South Atlantic, South Central, and Southeastern conferences. This study will take place in the Florida Conference.

The Florida Conference adopted the CCSS in 2012. In addition to the CCSS, there are standards that address faith and learning. However, the CCSS were adopted in its entirety. As with any change, it is important for the leaders - school officials - to lay the foundation for the implementers (teachers) to be prepared through the initial process and be ready to implement such change with fidelity in order for it to become institutionalized (Rothman, 2012a).

\section{Rationale}

The most challenging aspects of the CCSS are: the lack of training for teachers, the scarcity of information for parents, and the inadequate planning for resource allocation. The CCSS have commanded concerns, comments, and questions. There is no shortage of publications about the CCSS. There are pros and cons about them but much of the concerns are centered on the fact that teachers - and in many cases administrators - were not ready to implement the CCSS (Hall, 2014; Rothman, 2012b). 
Due to this lack of preparedness, teachers and administrators were not able to educate parents regarding the CCSS and how they would impact their children's education (Maunsell, 2014) — particularly in the area of assessment. Additionally, the CCSS were adopted so quickly that school districts did not foresee the cost of implementation in terms of classroom resources and assessment materials. Cost has been a great concern as well (Rothman, 2012a; Farmer, 2014).

\section{Statement of the Problem}

Scholars such as Rothman (2012b) and Hall (2014) found that US teachers perceived they lacked adequate knowledge to translate the CCSS into actions to support and promote higher student achievement. If teachers in the Adventist school system hold the same view, then most Adventist teachers did not feel ready or prepared to implement the CCSS. Consequently, the CCSS may only be paper documents sitting on shelves rather than concepts changing the dynamics of teaching and supporting student achievement in each classroom. However, there have not been any studies about the use of the CCSS by the Florida Conference Since their adoption in 2012. Similarly, no investigations in the Florida Conference have documented training processes, implementation strengths and challenges, or impact on teachers and learners. Thus, Adventist educators and administrators in the Florida Conference have no formally compiled data related to CCSS implementation that can guide decision making and strategic planning (Holloway, 2003). 


\section{Purpose of the Study}

Three primary purposes guided this qualitative case study. First, the study sought to examine the perceptions of teachers in regard to the adequacy of Professional Development to support the CCSS adoption by the Florida Conference. Second, it wanted to know how teachers were implementing the CCSS in their planning, teaching, and assessing. Finally, it desired to understand teachers' perceptions of the impact the CCSS were having on student learning.

\section{Philosophy, Research, and Observation}

For this study, the work of several individuals who have contributed in the field of education were used to provide insights and basis for a case study. I focused my study on the studies of: Hall and Hord's (2011) principles of change, Fullan's (2007) Process of Change, Professional Development principles of Joyce and Showers (2002), Dufour (2014), Guskey (2014), McTighe and Wiggins' (2004) Planning for understanding, and Murphy's (1995) whole faculty study group. The specifics of the framework will be detailed in the literature review of Chapter 2.

Change is learning (Hall \& Hord, 2011) and it is a necessary part of any organization. In order for deep learning to take place, the kind of learning that leads to real understanding and change, there must "a sequence of experience, reflection, abstraction and active testing" (Zull, 2002, p. 13). In order for deep learning to occur, there must be the realization that change is a process (Hall \& Hord, 2011) and that process involves such steps or phases as outlined by Fullan (2007). The first phase of the change process is the Initiation part where the decision is made to advance a change based on factors such as test scores, new philosophy or methods on teaching and learning, 
or any new policies or mandate. The second phase is the Implementation phase where the change is clarified and goals are set in regard to meet the complexity, demands, and the need for individual support that accompany the initialization of any change. The third phase is the Institutionalization phase where the change has passed the test of the initial and implementation time and has become ingrained into the system. It is now the way of doing things.

All three phases require that the people who are involved in the change be purposeful and intentional in their learning (Dufour, 2002). Especially for the learning that occurs at the classroom level. When a change is initiated at any level of an organization, it is important to remember that "successful change starts and ends at the individual level" (Hall \& Hord, 2011, p. 9. As "the classroom with all its limitations remains a location of possibility" (Hooks, 1994, p. 207). Professional Development is needed to ensure that school leaders are well versed and focused so that they are able to lead the teachers and impact student learning at the classroom teacher level (Eilers \& D’Amico, 2012)

\section{Research Questions}

Using the framework for this study, the research questions provided a way to gather responses about the perceptions of the teachers across the Florida Conference. Specifically, this study sought to research and respond to the following questions:

1. What are teachers' perceptions regarding the adequacy of their Professional Development to support the implementation of the CCSS?

2. How are teachers implementing the CCSS in the classroom in terms of 
planning, teaching, and assessing?

3. What are teachers' perceptions regarding the impact of the CCSS on student learning?

\section{Delimitations: Bounding the Case}

This study took a qualitative case study approach to investigate a specific or bounded system through the collection of detailed and thorough data using multiple sources of information such as interviews, observations, and document analysis (Merriam $\&$ Tisdell, 2016). The purpose of the study was to investigate the perceptions of teachers in the Florida Conference of Seventh-day Adventists regarding the adoption of the Common Core States Standards. In order to provide boundary to the study and all the possible people and things to analyze, a purposeful sampling of six teachers was gathered among the teachers of the Florida Conference. Further, criteria established for the success of this case study, was that the teachers had to have worked with the conference at the time of the adoption of the CCSS in the year 2012 and had to teach Language Arts and Math in grades $\mathrm{K}-8$. The six teachers were interviewed and among them, two teachers one Math and the other ELA - were observed. Documents such as lesson plans and pictures of anchor charts were collected from those classroom observations.

\section{Description of Terms}

CCCS: Acronyms for the Common Core State Standards which are a set of learning goals that schools can use to guide their instruction and assessments of students' ELA and Mathematics progress in Grades K-12. These are referred to as: The CCSS, the state standards, or just the standards.

No Child Left Behind (NCLB): The 2001 federal Public Law PL 107-110 enacted 
by President George Bush.

NAD: North American Division of Seventh-day Adventists

NGA \& CCSSO: National Governors Association \& Council of Chief State School Officers.

Professional Development: Forms of training where teachers participate with the purpose to learn, plan, and prepare to use a specific strategy, mandate, or standard. It may take the form of workshop, mentoring, coaching, etc. The purpose of teacher training is to ensure better learning for students. Greater achievement for students is at the heart of Professional Development.

Teachers: Educators from the Florida Conference who teach Reading, ELA, and Mathematics. Teachers represent those who teach in the K-8 since the year 2012 when the CCSS were adopted.

\section{Significance of the Study}

This study will be useful to leaders in the Florida Conference as they plan and implement new initiatives and the Professional Development to support them. It will also provide a direct view of the perceptions and insights into the thinking of the educators of the Florida Conference regarding the CCSS.

It is necessary for leaders who plan for changes to hear from the implementers about the status of the change. This study will provide a type of feedback to the Florida Conference on the progress of the CCSS. The conference will then be able to determine whether or not the CCSS are effecting the changes or meeting the objectives that they had in mind when they first decided to adopt them. Consequently, this will provide evidence to plan for continued training and checking of the CCSS. 


\section{Organization of the Study}

Chapter 1 begins with an overview of the study and its related focus - the CCSS. I provide a rationale for the study and state the problem and the purpose for the study.

Chapter 2 covers the literature framework, the significance of the study, and my personal interest.

Chapter 2 provides the literature review.

Chapter 3 describes the methodology used for the study.

Chapter 4 discusses case study findings from the data gathered from interviews, observations, and artifacts.

Chapter 5 concludes the study with conclusion and recommendations. 


\section{CHAPTER 2}

\section{LITERATURE REVIEW}

\section{Introduction}

For this study, I searched the database of the Andrews University library through the database for dissertations, through EBSCO Information Services, Educational Resources Information Center (ERIC), and ProQuest. I also searched in Google Scholar and in Google. I used the internet to go directly to the websites of www.achievethecore.org and www.corestandards.org for information regarding the CCSS. Additionally, books and journals provided great sources in order to situate the study within the framework of research and practice in the educational field.

An appropriate beginning for the review would be a brief history of the CCSS to provide the reader with the historical and educational contexts of the CCSS.

\section{The Development of the CCSS}

As long as we have been educating students, there have always been concerns and challenges which eventually lead to changes, reforms, and mandates (Rubinstein, 2013). For a foundational understanding of the CCSS, we must go back earlier to the 2002 Federal mandates of NCLB. Under the leadership of President George W. Bush, the NCLB mandate was enacted to require that each state establish its own set of standards and assessments by which to measure student academic achievements (Hess, 2014, 
Wallender, 2014). While all the states were mandated to adopt a set of standards, there were no specific guidelines for uniformity among them. Students from the various states, accordingly, received education that was more or less rigorous depending on where they lived (Meier, Finn, \& Schlechty, 2010; Newman \& Roskos, 2013). There were as many types of standards, curricula, and assessments as there were states and students who moved from one state to the other had no way to count on predictability and continuity in their learning.

During the year 2009, forty-eight states in our nation, along with two territories and the District of Columbia, gathered with their governors and states commissioners of education to work together with their organizations - the NGA Center for Best Practices and the CCSSO, to lead in the development of the CCSS. Teachers, parents, school administrators, and experts across the country, together with state leaders, provided input into the development of the CCSS (NGA \& CCSSO, 2010). These associations relied on the support and participation of associations such as the National Education Association, American Federation of Teachers, National Council of Teachers of Mathematics and National Council of Teachers of English. The CCSS were constructed based on best practices among the Nation's schools and on the examination of the expectations held by countries around the world that are high performing. Careful research and available literature on what students need to know and be able to do in order to be successful in college, career, and life also aided in the establishment of the CCSS (NGA \& CCSSO, 2010). While selected groups of professionals worked in establishing the standards, the mass numbers of educators and the public were not involved or informed about them until later. 
In June 2010, the CCSS were introduced to states and educators. The CCSS are a set of ELA and Mathematics learning goals that describe what students should know and be able to do at every grade level from Kindergarten-12 grades (Edwards \& Springs 2014; Eilers \& D’Amico, 2012; Hess, 2014). The purpose of the CCSS is to establish a rigorous set of goals that each state can adopt in educating their students. Moreover, the CCSS ensure that students who relocate will have a consistent and coherent education that builds and continues in a uniform manner (Edwards \& Springs, 2014).

The CCSS are comprised of clear career and college ready standards that will prepare students for the world of work and global competition (Conley, 2011; Farmer, 2014, Wallender, 2014). They are not meant for students alone. The CCSS establish a basis for communication, collegiality, and collaboration among educators across the nation (Brooks \& Dietz, 2012-2013). They also provide the foundation for educators to assess their students. That is an important point since the CCSS do not prescribe a way for teachers to instruct and assess their students and to develop their own repertoire of teaching; they provide a common ground for educators to work together to establish curriculum, assessments, and Professional Development that supports them in meeting the goals and purpose of the CCSS.

\section{The CCSS and Prior Standards}

\section{Major Shifts in English Language Arts}

The CCSS differ from other educational reforms in that they reflect some shifts in expectations for ELA and Mathematics. The main shifts for ELA are:

1. Students must increasingly have regular practice with complex texts that will 
prepare them to meet the demands of college and career. By increasing complexity through the grades, students are able to move through the grades with confidence and gain in their literacy ability. Vocabulary is very important within that shift. Students should muscle their vocabulary skills through the use of mixed conversation, direct instruction, and reading. The CCSS also ask students to define and understand word meanings, notice the different shades in words, and to consistently broaden their range and use of words and phrases (Alberti, 2012; Blosveren, Liben, \& DeWitt, 2014; NGA \& CCSSO, 2010; Shannahan, 2012).

2. Reading, writing, and speaking in the ELA must be grounded in evidence from texts, both literary and informational. Instead of asking students to respond to literature based on their background, experience, and knowledge, students' responses must be grounded in evidence from the texts - whether informational or literary. They must be able to read and present concise analyses, defend their claims, and provide clear information from what they read. Students must garner the ability to read and use evidence within the text to gain information, ideas, arguments, and details. Consequently, they are able to answer questions that are text-dependent (NGA \& CCSSO, 2010).

This standard also applies to writing. Students from Grades K-12 often write based on their opinions or experiences which alone cannot prepare them for the world of college and career. The standards expect that they must also write based on evidence and be able to inform and persuade (NGA \& CCSSO, 2010).

3. Student must increasingly focus on gaining knowledge through non-fiction text that is rich in content. In order to be successful readers, students must have a strong and wide foundation in general and world knowledge and vocabulary. Those skills are 
gained through constant exposure to informational texts. The CCSS call for a 50-50 balance between non-fiction and fiction text in the $\mathrm{K}-5$ classrooms in order for students to gain important content knowledge from the social sciences, science, arts, and technical studies. This forms the building block for students in Grades 6-12 as the CCSS require a greater attention to nonfiction reading and an integration of reading, writing, listening, and speaking into every subject area (NGA \& CCSSO, 2010).

\section{Major Shifts in Mathematics}

The CCSS for Mathematics differ in some fundamental ways as well. The three major shifts are:

1. Students will have a greater focus on fewer topics. Instead of working through a wide variety of topics, the CCSS call for students to work through the curriculum in depth. The CCSS divide the work into specific skills and concepts for each grade level. For Grades K-2, the students will learn concepts, skills, and problem solving that are related to addition and subtraction. In Grades 3-5, the CCSS focus on concepts, skills, and problem solving that are related to multiplication and division of whole numbers and fractions. Grades 6 focuses on the relationships of ratios and proportions and early algebraic expressions and equations. In Grade 7, the CCSS deal with proportional and ratios relationship and the arithmetic of rational numbers. Finally, Grade 8 covers linear algebra and functions which are important to prepare the students for high school.

2. The subject matter will focus on the coherence of learning. Students will be provided with continuity in Mathematics learning across the grades. A set of standards from one grade lays the foundation for the next grade. Standards are connected carefully in order to close any gap that student may have in learning. 
3. Students will experience rigor in their learning of Mathematics. The CCSS require that students possess great depth and true command of the concepts in Mathematics (Alberti, 2012; NGA \& CCSSO, 2010). The CCSS focus on fostering conceptual understanding, procedural skills, and fluency which help students to view Mathematics holistically. Rigorous learning of mathematical concepts provides the foundation for students to apply their mathematical knowledge accurately and in various situations.

\section{Perspectives on the CCSS}

The Proponents of the CCSS

The CCSS have been hotly debated in many different venues. There is no shortage of writing and opinions when it comes to the CCSS. For this study, I looked first at the positive views of the CCSS and I discussed the negative points next. This discussion is in no way exhaustive, as articles, comments, and books abound in the subject of the CCSS. This study offers a succinct and summarized view of the positive and negative points of the CCSS as viewed in this educational as viewed in this educational research context.

\section{Common Response to a Common Concern}

The CCSS are a set of standards that was developed in response to a common concern that students in the U.S were slipping behind the rest of the world in academic prowess (Extrom \& Thatcher, 2014; Tepe, 2014)). The developers wanted a set of standards - a progression of learning expectations in ELA and Mathematics designed to effectively prepare students in Grades K-12 to be ready for college and career (Edwards 
\& Springs, 2014; Newman \& Roskos, 2013).

The CCSS would describe with clarity what students should know and be able to do after they leave high school and enter the world of work (Edwards \& Springs, 2014) consequently, the CCSS must be somewhat universal. Not completely universal because states or private institutions can add those goals which are important to them to the CCSS. However, the goal is for all students to be able to meet a set of common goals that would yield the same benefits to them no matter where they attend school.

Prior to the CCSS, there were as many standards as there were states (Jacobs, 2010); yet students and their families are less stationary than in the past. They move not only within states but without as the world becomes smaller and smaller. Therefore, the CCSS by their universality have the goals to maintain uniformity for students who move from state to state to be instructed and evaluated based on a common set of goals and expectations (Blosveren et al., 2014). Also, through increased rigor and a greater stress on quality education for all students, the standards hold the possibility and hope of preparing them "for a world where the opportunities for success require the ability to compete and cooperate on a global scale" (Jacobs, 2010, p. 97).

\section{Negative Views of the CCSS}

Opinions vary from the CCSS being a very bad idea to it being downright insane (Hall, 2014; Ohler, 2013; Yatvin, 2013). While thoughts abound on that subject, most ideas are clustered around some definite concerns that pertain or are relevant to the Florida Conference of Seventh-day Adventist school system.

The first concern surrounding the CCSS relates to a basic lack of familiarity in the general public and even more troubling, among teachers. According to a Phi Delta 
Kappa/Gallup poll, only 38\% of American citizens had ever heard of the CCSS (Hess \& McShane, 2014). Teachers across the states complained that they were not adequately prepared, nor were they asked about the CCSS. That complaint caused many state teachers' union to withdraw support for the CCSS. State legislators share the same grievance of not being consulted or involved in the creation of the CCSS (Exstrom \& Thatcher, 2014). There was minimum public engagement in the development of the CCSS (Farmer, 2014). While some educators participated in the development of the CCSS, their representation was very limited. The mass of educators who would be responsible to implement them were not involved or prepared. The lack of familiarity and preparation has caused many to have no knowledge or, at best, a faulty understanding regarding the CCSS.

Parents also were not familiar with the CCSS. Since school officials did not know much about the CCSS, it is inevitable that parents too would remain in the dark about the new them inasmuch as they depend greatly on school administrators and teachers to educate them about new school reforms and initiatives. Consequently, parents were also left to surmise and suppose about the new school standards. This concern affects public school parents and to a higher degree, private school parents who have not been required to follow or enter public debates. In a sense, the CCSS, just as many other reforms, were developed with the public schools in mind. However, private schools do not operate in isolation (Davies, 2014). They too must prepare their students for college and career. It stands to reason, that they might join —as the Florida Conference has done—with the public sector to ensure that our standards are congruent with the population where we operate. In response to questions about the CCSS and its relationship to the work in the 
Southern Union, Debra Fryson, Director of Education for the union, states: "The CCSS wants what we all want. They want kids to think deeply. They want them to apply what they are learning. And so, do we. But we are taking it so much further. We never settle for what the world wants. We are educating our children for eternity. The Core Curriculum for Seventh-day Adventists has recently been revised to include the best of all worlds. Not only are we asking our students to think deeply, apply their learning, write for meaningful audiences, think critically as they read, master and apply mathematical principles, but all of this is done within the unique context of our Adventist worldview. Learn more about our Adventist curriculum by visiting www.adventisteducation.org/about/adventist_education.core-curriculum.

Many private schools' parents and teachers listen to concerns-perhaps misguided — from those who oppose the CCSS and they spread those concerns among their schools and beyond. Private school stakeholders may not be aware of all the history behind the public debates or they might not have all the information from all sides of the debates to think critically and intelligently about the CCSS. Consequently, they worry and conjure arguments that the CCSS are not good—or even evil—for the children in the various religious institutions.

\section{Political Contribution to Negative Views of the CCSS}

Politics have played an important role in how people criticize, judge, or distrust the CCSS and the intent of those who designed them. State officials constructed the CCSS as a way to provide an education that is consistent across the nation and that will prepare students upon their high school graduation for college and career. This idea was not new with the CCSS developers. Years before the 1996 National Education Summit, a 
bipartisan group of corporate and state leaders decided to establish and create an organization-Achieve - that will support the educational reform across the states (Hess, 2014, Rust, 2012). That organization would eventually lead to the creation of the CCSS. Presidents Ronald Reagan, Bill Clinton, and George W. Bush, all supported the idea of creating a set of stringent and largely defined academic concepts in English and Mathematics for American students at the start of their schooling in Kindergarten to the end of their high school years (Edwards \& Springs, 2014). They believed for example, that a child in Kindergarten, living anywhere in the United States, should be able to count by one or ten from one to one hundred; or a child in the third grade, given the length of the sides of a shape, should be able to figure out the perimeter of that shape.

The idea of a common set of standards was not new nor was it limited to one political party. Many Americans were concerned that children in the United States were lagging behind those of other nations. American students were not prepared to meet the demands of college as indicated by the number of students who needed remedial classes upon entrance in college. In 2009, the Program for International Student Assessment, an assessment that evaluates the reading, Mathematics, and science skills of 15-year-olds in industrialized countries, showed that students in the United States lacked reading skills and lagged behind China, Korea, Finland, Hong Kong (China), Singapore, Canada, New Zealand, and Japan. Additionally, in Mathematics, they fell behind: Shanghai (China), Singapore, Hong Kong (China), Korea, Chinese Taipei, Finland, Liechtenstein, and Switzerland. They ranked $17^{\text {th }}$ in the world in reading, $23^{\text {rd }}$ in Science, and $31^{\text {st }}$ in Mathematics (Munson, 2011). Americans were concerned including President Obama. However, thoughts about the CCSS changed shortly after they were developed. The 
Obama administration unveiled a stimulus package to the country (Edwards \& Springs, 2014; Hess, 2014; Hess \& McShane, 2013) and part of that package would include grants that states - through competition, could gain for their schools to help promote educational progress. In 2009, the President made the following statement:

America will not succeed in the 21st century unless we do a far better job of educating our sons and daughters.... And the race starts today. I am issuing a challenge to our nation's governors and school boards, principals and teachers, businesses and non-profits, parents and students: if you set and enforce rigorous and challenging standards and assessments; if you put outstanding teachers at the front of the classroom; if you turn around failing schools - your state can win a Race-to-the-Top grant that will not only help students outcompete workers around the world, but let them fulfill their God-given potential. (Obama, 2009)

The Race-to-the-Top funds would be granted to states who adopted standards that prepared students for college and work and that were consistent across states. While the states did not need to adopt the CCSS to compete, the CCSS resounded with the requirements for the grant. The standards were rigorous, common across states and promoted collaboration and Professional Development for teachers. States who would receive the grants would need to have standards that had the same tenets as the CCSS. Many states, about 46 of them, and the District of Columbia (DC) competed for the grants and eleven states received awards that ranged from 75 to 700 million dollars. The eleven states included: Delaware, DC, Florida, Georgia, Hawaii, Maryland, Massachusetts, New York, North Carolina, Ohio, Rhode Island, and Tennessee. The state of Florida received the highest award of $\$ 700$ million dollars.

The Race-to-the-Top grant created a problem. Many people believed that the federal government was too involved in leading and managing schools which is the duty of states (Edwards \& Springs, 2014). Moreover, the federal government funded two groups of states to create tests that would match the CCSS. The Obama administration's 
participation and perhaps the timing of the grants so close to the establishment of the CCSS did not allow for people to understand the difference between the grants and the adoption of the CCSS. The government was vastly criticized for its support of the CCSS and for offering states the opportunity to compete for funds based on their adoption of the CCSS or standards that were congruent to the CCSS. The view was the federal government — specifically President Obama — was intruding into the educational affairs of state and local schools (Edwards \& Springs, 2014). This contributed to the negative perceptions about the CCSS (Finn \& Brickman, 2014).

\section{Florida's Response to the CCSS and Race-to-the-Top Grants}

According to the Florida Department of Education website, the Florida State Board of Education adopted the CCSS year on July 27, 2010. Full implementation began in the 2013-2014 school year. However, the public expressed many concerns and offered various comments regarding the CCSS and their implementation which prompted the school board to make changes and adjustments to the CCSS. The changes resulted in the current set of standards: Mathematics Florida Standards and Language Arts Florida Standards, which were approved on February 18, 2014.

Even with the changes, the tenets of the Florida standards match those of the original CCSS. Both have the same main goals: to provide opportunities for Florida students to gain the necessary knowledge and skills needed to be successful in college, career, and life.

Florida was among the eleven states and the DC, Delaware, Georgia, Hawaii, Maryland, Massachusetts, New York, North Carolina, Ohio, Rhode Island, and 
Tennessee - that applied and received the Race-to-the-Top grant. According to awards guidelines, the awards go to the states that lead the way with goals that are ambitious but attainable. Florida received the highest amount among the applicants: $\$ 700$ million. In March 2011, the Florida legislature passed the Student Success Act which matches many of the goals that were in the application for the Race-to-the-Top awards.

The Florida Department of Education has used the grant money in the following ways:

1. A gifted Science, Technology, Engineering, and Mathematics program was created to meet the needs of bright students in the rural areas which provides summer challenges and mentors for those students living in those areas.

2. New principals and vice principals (140) were prepared for employment in the districts that partner together to implement standards that prepare students for college, career, and life.

3. Minority students have been recruited to become and serve as teachers.

4. Florida currently directs a databank of information that contains research in science, technology, English, and Mathematics along with assessment for educators to share.

\section{The Importance of Professional Development}

Professional Development is imperative to any change especially for the CCSS where teachers are required to look at teaching in different way than before (Sawchuck, 2012). "An indisputable fact that should drive educational reform is that what really influences how students learn is the effectiveness of the teacher" (Culham, 2014, p. 20). Thomas Guskey, a professor of educational psychology at the University of Kentucky’s 
College of Education, explains that "teachers will teach as they were taught and if they are going to incorporate these ideas in their teaching, they need to experience them as students" (as cited by Sawchuk, 2012, p. 20). "We don't want to just bring superficial understanding of these standards but to deepen the understanding, so we have an opportunity to deliver instruction in a way we haven't before" (Sawchuck, 2012, p. 16).

Teachers must have a good understanding about the CCSS in order for them to develop and choose the appropriate approaches that are necessary to teach the concepts that are in the CCSS (Extrom \& Thatcher, 2014). For teachers to be successful implementers, they "must be fully equipped to elevate the CCSS from mere words to tangible improvements in learning" (Griffith, 2014, p. 95). They need more time to collaborate and to develop and learn together (Lattimer, McBride, \& Combs, 2010; MacGilchrist, 1996; Rotherham \& Willingham, 2009). There must be more "opportunities for teachers to fill the learning gaps for students and to challenge those who are ready" (Berkowicz \& Myers, 2013, p. 3).

Professional Development takes time. "Successful change often takes a number of years" (Sterrett, 2011, p. 51). It is not enough to gather teachers in one place and declare the adoption of a new set of standards. Educators must have the time necessary for them to collaborate on new curriculum and to plan the best instructional practices that will ensure their-as well as their students' success (Center for Public Education, 2013). Dorothy Strickland (2010) says it clearly: "It will take a great deal of Professional Development ... [which] will help educators, teachers, and administrators to understand the CCSS and their implication for instruction and then put that knowledge into action" (as cited by Hall, 2014, p. 19). 
Professional Development must address the factors that are necessary to implement the CCSS successfully. Those factors include instructional and assessment decisions along with the materials and technology that facilitate implementation. Teachers must decide daily about how to teach and meet the needs of their students. It is imperative that those decisions are made based on student performance data in order to design the appropriate professional learning that will enable teachers to move student learning and progress forward. The main goal for professional development is to impact student learning and analyzing student data would assist school leaders in identify the necessary Professional Development needs of their teachers as well as having the benefit of monitoring change efforts (Holloway, 2003).

Time and resources must be allocated to secure instructional materials and assessments that are related to the CCSS. It is important to align instruction to assessment because "if teachers aren't teaching what is going to be on the test, when poor test results come, we can't tell if students were taught what they needed to know but did not learn it or if students weren't taught what they needed to know" (Hess \& McShane, 2013, p. 63). "Instruction, materials, and Professional Development ought to align by the time [the] new assessments 'count' for the purpose of evaluation"' (Hess \& McShane, 2013, p. 65). However, this has not been the case. "These standards which hold such potential to create deeper learning, are instead creating serious backlash as [school] officials seek to make them count before they make them work" (Weingarten, 2013, as cited by Hess \& McShane, 2013, p. 65).

\section{Misunderstanding of Ownership}

While many organizations such as the U.S. governors, state superintendents, and 
teacher groups were involved in creating the CCSS, this involvement did not include the vast majority of teachers and administrators in the field through Professional Development. Teachers needed to have the opportunity, resources, and time (Bond, 2011) to gain a deep understanding of the CCSS. "People don't change unless they have ownership of the change" (Schwahn \& Spady, 1998, p. 45). Those trained educators would have in turn, been better able to teach parents about the CCSS.

Parents do not know how the CCSS affect teaching. Consequently, they believe the CCSS to mean that "teachers are having their curriculum dictated to them by the federal government" (Schaffhauser, 2014, p. 27). They are not familiar with the expectations for learning and how they can best support their children and how to prepare for the CCSS and all the ensuing changes in technology, instructional materials, and assessments (Newman \& Roskos, 2013).

There is the perception of a lack of public knowledge about who truly owns or is responsible for the development of the CCSS. While the states have been involved since the inception of the CCSS in 2007, the federal government became involved in February of 2009 when it announced that it would provide Race-to-the-Top funds as a competitive incentive for states to adopt the CCSS (Exstrom \& Thatcher, 2014) or any standards that focus on preparing students for college and career. In return, states that adopt would not be held responsible for the prior obligations of NCLB which demanded that schools meet Annual Yearly Progress. In 2010, the federal government awarded two groups of states a total of $\$ 330$ million to develop new assessments that would address the requirements and measure the success of the CCSS. The government involvement, more than anything else, has fostered parents' belief that the CCSS is a vehicle employed by the government 
to control the states — and by extension — people's lives.

\section{Framework for Teacher Support}

The shifts in ELA and Mathematics require that teachers approach teaching differently in order to meet the requirements of the CCSS. It is not enough to pass a mandate or declaring new rules about teaching. These will not help teachers to know and understand their work in fresh new ways (Berkowitcz \& Myers, 2013) and to become full participants in the change process (Betts, 1992). Therefore, it is essential to lay the foundation for teachers and to help and support them through the implementation of these CCSS.

The framework for the literature review on teacher support is centered on the ideas of change and change support: facts about change (Hall \& Hord, 2011), the steps of change (Fullan, 2007), change evaluation (Guskey 2002), and on the concept of teaching for understanding and Backward Design (Guskey, 2014; Wiggins \& McTighe, 2006). First, I discuss some principles of change that educators must keep in mind when planning for change. Then I discuss the steps to change; the way to evaluate change; and the concept of understanding by design. Finally, I took a look at the role of culture in schools.

\section{Principles of Change}

Hall and Hord (2011) espoused the idea that change must be based on ten principles:

Principle 1: Change is learning. When a new change is introduced, it is learning that makes it possible for it to go forward. "Professional learning is a critical component 
embedded in the change process" (Hall \& Hord, 2011, p. 6).

Principle 2: Change is a process, not an event. Change is not possible after an announcement by a leader; a two-day training workshop for teachers; or the procurement of new curriculum materials. "It is a process through which people and organizations move as they gradually learn, come to understand, and become skilled and competent in the use of new ways" (Hall \& Hord, 2011, p. 8). It is not a quick fix, rather it is a process which takes three to five years to be implemented at a high level. Accordingly, a great deal of planning must go into the change process. Planning must be strategic and purposeful by allowing the necessary time - three to five years- for successful implementation and by budgeting appropriate resources for learning and on-site coaching throughout this time.

Principle 3: The school is the primary unit for change. The school is where change lives or dies. It is the single most important unit for the success of change. "The school's staff and leaders will make or break any change effort" (Hall \& Hord, 2011, p. 9) no matter who or where the change was initiated. It is necessary then for everyone involved — district office, principal, and teacher - to work together to obtain support such as professional learning in order to understand their role in the change implementation.

Principle 4: Organizations adopt change; individuals implement change.

"Successful change starts and ends at the individual level" (Hall \& Hord, 2011, p. 9). The individual must be considered during the change process to the extent that it is feasible and beneficial to the person, the organization, and the learning process. Svinicky (2004) explains that "Humans are very complex organisms with lots of variables impacting their behavior [or learning]" (p. 177). With this complexity comes a great deal of variations 
when it comes to learning. Not all people will learn at the same pace and with the same acuity which is why it is important to allow time and resources (Bond, 2011) for individuals to learn and for that learning to impact their practice and targeted outcomes during the change implementation.

Principle 5: Interventions are key to success of the change process. There are different kinds of interventions. Without them, change is impossible (Hall \& Hord, 2011). The most common one is training workshops but small interventions such as the onelegged interview is very efficient in supporting the change process. It is small opportunities, passing in the hallways for example, for the principal and teacher to speak briefly about how the change is going.

Principle 6: Appropriate interventions reduce resistance to change. Facilitators of change must have a clear understanding of the details of the change and what it requires to lead in the change process. It may be hard for some people to adopt to change. People may resist change because they are being asked to leave what is comfortable and move onto the unknown or they may resist because they really doubt that the change is necessary, warranted, or useful. They may have limited understanding of the new change or they may have "solid reasoning and evidence" (Hall \& Hord, 2011, p. 13). Change leaders must know how to facilitate and lead the people into learning about the change and its implementation in order to reduce the resistance that may come with change.

Principle 7: Administrator leadership is essential to long-term change success. Administrators play a key role in supporting and maintaining change. Very few bottomup initiatives, such as the writing workshop initiative survive; without leadership on the part of the administrators, change efforts are more likely to die. Administrators must 
work daily to support and to provide continuous learning about the change (Hall \& Hord, 2011, p. 14) in order for it to be long-lasting.

Principle 8: Facilitating change is a team effort. All hands must be on deck when a school is implementing a change. Principals must fulfill their crucial roles along with all others involved and the teacher's role is vital for the success of the innovation. "Leadership must be ongoing for change to be successful” (Hall \& Hord, 2011, p. 14). Everyone must help and support with the same goal in mind which is the success of the change process.

Principle 9: Mandates can work. A mandate is a form of intervention in a change process. Often, mandates are frowned upon because people look at them as dictates or top down orders. Mandates, however, are not the problem. The trouble comes when a mandate is supported at the initial announcement and everyone is left to figure out the change. In order to be effective, mandates must accompany communication, learning, coaching, and sufficient time for implementation. Mandates are specific, their priorities are clear, and there is the expectation that the innovation will be implemented.

Principle 10: The context influences the process of learning and change. There are two aspects that affect changes in a school. The first is the physical aspect, including the arrangement of the place, dimension, policies, resources, schedules, and structures (Hall \& Hord, 2011). The second aspect is the people factors which are the beliefs, attitudes, and values of the people involved, and the relationships and norms that guide their behavior.

Hord and Hall (2011) in their development of the Concern-Based Adoption Model, addressed the relationship between the organizational change and personal 
concerns that persons within the organization may experience. Concerns might be on something else (Stage 0 ), on the self (Stages $1 \& 2$ ), on the task (Stage 3), or about the impact that the individual may have on the change situation (Stages 4-6). It is important for change leaders to understand and evaluate the stage where people in their organization may fall in order to provide the support necessary to be successful through change. These concerns are characterized by the various stages that a person goes through in the process of change:

0: Unconcerned Stage: There is little or no involvement with the change. The person's concern is elsewhere.

1: Informational Stage: The person would like to know more about the change initiative

2: Personal Stage: The person takes a personal look at the change and wonders how using the innovation will affect him/her

3: Management Stage: A lot of time is spent with the planning, preparing, and managing materials for the innovation

4: Consequence Stage: The person takes an outward look of the use of the innovation. How is the use affecting others like the clients?

5: Collaboration Stage: Here, the focus is on personal practice in relationship to colleagues working in collaboration with others.

6: Refocusing Stage: The person extends the practice to others. The individual has ideas and is reflective in his practice. He is able to share ways-better or more constructive - to implement the change (Hord \& Hall, 2011). 


\section{Fullan's Steps to Change}

According to Fullan (2007) there is a process to change and it consists of three phases over time. The first phase is the initiation part. It is at the beginning of this stage where it becomes apparent that change is necessary and that the need for the process is warranted. It may be initiated by one person or several individuals who are invested one way or another in the change. It may be based on factors such as: the presence of low standardized scores, parental or community influences; an advocate or external change agent; or new policies or findings.

The second phase is the implementation phase. It is where the people who are involved in the change put their ideas into practice. It is very important that there be a clear understanding of the needs for change in order to execute in a way to meet them. The presence or absence of certain factors may foster or hinder this process: clarity of goals is needed in order for all involved to have a clear understanding of the goals. Another factor is the complexity which is the strain and magnitude of change that people must go through during this stage. Hardship may create problems, but it can also be a stepping stone to better and greater change.

The last phase is the institutionalization stage which determines whether the change becomes part of the fabric of the organization or if it dies. Lack of support and interest may affect the change negatively. Change makers must ensure that people are interested, that the change becomes a part of the structure, that members are committed to change, and that there are established procedures to support the continuation of the new change (Perkins \& Reese, 2014). 


\section{Planning for Understanding and Backward Design}

Backward Design is a move from the traditional way of planning units and the lessons derived from them. It is a framework for educators to plan with the sole intention and purpose that students will understand and transfer their learning into meaningful and relevant use in the common areas of life. With this purpose in mind, the teacher plans backward from the identification of desired results to the determination of acceptable evidence, and to finally the planning of the learning experiences and activities.

According to McTighe and Wiggins (2004), Backward Design allows educators and curriculum designers to "state with clarity what the student should understand and be able to do as a result of any plan" (McTighe \& Wiggins, 2004, p. 14). It helps to answer very important questions about the learning that the students are expected to acquire. It answers from the teachers such as: What is the point here? What are the big ideas guiding the teaching? What is the plan to ensure the learning? Additionally, the design answers students' queries as well: “To what does this relate? What does this learning help us to understand and be able to do? Why should we learn this?” (p. 16).

Backward Design is based on three main stages of planning. The first stage is to identify the desired results. This is where the teacher decides which goals the students should meet as a result of this learning. Looking at the goals, a set of standards, and curriculum expectations, and the teacher must decide clearly and exactly what the students should know, understand, and be able to do in the space and time allotted for the unit. Choices must be made carefully so the most important, worthy and enduring knowledge must be selected during that stage.

The next stage of planning backward is to determine acceptable evidence. This 
stage answers how well the students are marching toward and meeting the desired results. Teachers must decide how they will know where the students are in meeting the goals and what evidence will be accepted and verified as proof of students' understanding and proficiency. Here teachers must, with an eye on the desired results, choose the tasks, types of assessments, and thinking students must show as evidence of reaching the goals.

The third phase is to plan learning experiences and activities to provide the knowledge and skills necessary for the students to know, understand, and be able to do that which will serve as evidence of reaching the stated and desired results. Throughout the planning process, teachers must think, decipher, and choose the best learning activities that will provide the knowledge and comprehension for the students to do and transfer their learning as they explain, interpret, apply, gain perspective, develop empathy, and gain self-knowledge (Wiggins \& McTighe, 2006).

This type of planning for understanding and purpose deviates vastly from traditional planning where educators commit, according to Wiggins and McTighe (2006), the "twin sins" of activity-focus planning and coverage. When planning for activities only, teachers would have a topic, choose the resources, activities, instructional methods, and finally administer a test. This activity_focused design provides for "engaging experiences that lead only to accidental, if at all, to insight and achievement" (p. 16). Similarly, when teachers lead their students to careen through the textbook or lecture without specific goals and desired results in mind, learning for understanding is not the focus as there is "no guiding intellectual purpose or clear priorities to frame the learning experience" (p. 16).The act of engaging in aimless activities and assessing at the end of the unit with the students' eyes and mind unfocused and ignorant of the desired results 
does not answer the "why" and "so what" of learning. "Without explicit and transparent priorities, students find the day to day work confusing and frustrating" (p. 16). The principle of Backward Design applies no matter the planner, the learner, and the goals. It applies then to planning and preparing teachers (Guskey, 2014; McTighe \& Thomas, 2003; McTighe \& Wiggins, 2004; Wiggins \& McTighe, 2006) for a change such as the adoption of the CCSS. School leaders must define the evidence that will indicate that the professionals have learned the necessary and anticipated knowledge or skill even before the activities are planned (Guskey, 2014).

\section{Culture, Communication, and Cooperation in Change}

Culture is an important consideration when it comes to implementing change. The Adventist school system as a Christian organization operates with a theistic worldview where beliefs and actions are directed by a transcendent, sovereign, and good God (Sire, 2009). This philosophy places man as a created being in the image of a personal, intelligent, and all-knowing God who has imbued men with His characteristics. "The foundation of human knowledge is the character of God as creator" (p. 36).

In Christian Theism, the omniscient and loving God has revealed Himself in the flesh in the person of Jesus. Though sin has marred the true character of God in His creation, "The Bible records God's love for us in searching us out, finding us in our lost, alienated condition, and redeeming us by the sacrifice of his own son Jesus Christ" (Sire, 2009). This is the work of redemption and the example to follow in leading educators through change.

In coming to save us, Jesus also "came to show how men are to be trained as befits the sons of God" (White, 2003, p. 49). He is the Master Teacher-the teacher sent 
from God.

It is important to understand the nature of culture and its role in change. "Teaching is at its core a moral profession" (Fullan, 1993, p. 12). As Christian educators, we find our morality in the person of Christ (Sire, 2009). Therefore, in approaching culture, it is important to note that "Teaching is both an intellectual and a moral profession" (Fullan, 2002, p. 18). In addressing the culture, change implementers are able to address both the mind and the heart. "A new heart ... will I give you, and a new spirit will I put within you” says God in Ezek 36:26 (New International Version).

In the process of initiating and implementing change, leaders should seek to know the culture - the heart of the people - in which the seed of change will be deposited and to be able to adjust or cultivate the kind of culture that is fertile for change to take root and grow (Barth, 2002; Brooks \& Dietz, 2012-2013; Fisher \& Frey, 2012; Fullan, 2002). "Every school has a culture, some hospitable, some toxic" (Barth, 2002, p. 6.) In their book, School Culture Rewired: How to Define, Assess, and Transform It, Steve Gruenert and Todd Whitaker (2015) define culture as the personality of the school. It is connected to climate in that the culture shows up through the attitude of the school. They share that "culture influences our values and beliefs; climate constitutes those values and beliefs in action" (p. 22). "A school culture has far more influence on life and learning in the schoolhouse than the president of the country, the state department of education, the superintendent, the school board, the principal, teachers, and parents can ever have" (Barth, 2002, p. 6).

School culture takes time to improve and change. "Educational change requires more than strategies, it also requires ways to anticipate and overcome obstacles to sustain 
change over time" (Hargreaves \& Fink, 2004, p. 30). This is not to suggest that change leaders wait for a culture to be at its greatest in order to bring changes. It does propose that leaders must be aware and understand the characteristics of the culture in which they work and be able to predict the reaction of each teacher in response to a particular or substantive change. Moreover, change leaders must work to change the undesirable elements of the current culture and to replace them with desirable qualities (Barth, 2002). As Fullan (2002) aptly puts it: "Reculturing is the name of the game. Transforming culture - changing what people in the organization value and how they work together to accomplish it—leads to deep and lasting change" (Fullan, 2002, p. 17).

Gruenert and Whitaker (2015) describe the different types of culture as follows:

Type 1: Collaborative. This type of culture is the "theoretical nirvana of school cultures" (p. 50). In this environment, learning is embraced for all students and adults alike. Teachers in this culture share strong educational values. They work in collaboration to pursue Professional Development opportunities that will support them in their commitment to work improvement. The collaborative culture is correlated directly to student achievement (Gruenert, 2005).

Type 2: Comfortable Collaborative. This is a very common type of culture. Many schools believe, perhaps rightly, that they work in such a culture. It is characterized by friendliness and good manners where teachers share advice, and teaching tips instead of asking important questions about their work and how they might improve. The lack of reflective interactions and feedback makes this environment incongruent to a true collaborative situation.

Type 3: Contrived-Collegial. In this culture, the principal or leaders of the school 
sets the pace for collaboration and improvements by introducing strategies and policies for the staff to follow. This culture is intended to support new teaching techniques and approaches, but the principal must be careful not to rush things along and cause frustration or loss of traction. It is best to take cue from respected teachers who often understand and catch the vision of the leadership and consequently, lead others to change. It takes time for culture to change and for people to have ownership in that culture.

Type 4: Balkanized. This culture encourages competition among small groups. They may compete for resources, position, or territory. This may result in cliques which may grow in strength to the detriment of the organization. Stronger groups may rise against any initiatives from the leadership and may also lord over the weaker groups.

Type 5: Fragmented. This environment encourages competition among individual teachers. Teachers may be polite with each other but the work they do is kept private. They do not share any professional interaction nor do they discuss student achievement and best educational practices. In the age of accountability and performance pay, teachers may be reluctant to share any of their secrets and opt instead to do their own thing without each other, the community, and the principal.

Type 6: Toxic. All schools should aspire to achieve a collaborative culture. At the absolute opposite is the toxic culture. Schools should try to avoid a toxic environment at all cost. "A toxic school culture expends energy on preventing change" (Gruenert \& Whitaker, 2015, p. 62). Rather, teachers often work together to protect what they most value - themselves. They may humiliate students, bad mouth their colleagues and leadership, and blame others - parents, students, and the community for their lack of success. Teachers in that kind of culture may be quite confident and seemingly 
professional. They are adept at hiding their beliefs which makes it hard to identify the dysfunction right off. Teachers may become strong in shunning responsibility and in their resistance to Professional Development and change.

It is important for leaders to possess a keen sense of cultural understanding. At the heart of a collaborative culture is the practice of communication-conversations among change leaders and between change leaders and implementers. It is "only through communication can human life hold meaning" (Freire, 2011 p. 77). If peopleadministrators, teachers, and students - matter most in the process of change, then communication and cooperation should go hand in hand. Communication and cooperation are made possible when a school has established a culture of collaborative learning or a Professional Learning Community (Dufour, 2004). If educators are provided the professional development necessary for them to be successful, that will contribute to a positive culture at the school.

\section{Change and Professional Development}

Professional development is vital in the change process. Change is better supported when the whole school is a fertile ground for progress. When the people who are in charge of educating children decide to evaluate and to identify what they need in order to create better learning situation for the students, then they form a community where teachers learn in order for the students to learn well. This kind of learning community is possible with "supportive and shared leadership" (Hall \& Hord, 2011, p. 27).

When planning professional learning, Guskey (2014) recommends that educators place a significant importance on how the planning begins. "We must begin with the end 
in mind" (Covey 1989, p. 102). It is safe to assume that the main goal for change in school is centered on student achievement or progress (Dufour 2004, Reeves, $2007-$ 2008). If that is the case, educators, in planning for change, must start with student success in mind. They must plan backward to begin where they want to end up (student success) and work back from there to how they will ensure the desired success. Guskey (2014) advocates five steps for professional learning planning:

The first step is Desired Student Learning Outcomes. During this step, the outcomes must be clarified and appropriate evidence for the success of those outcomes must be determined. Start focusing on the results and establish the processes by which those results will be obtained. Those outcomes must be based on sound research and multiple results from evidences such as standardized tests, performance tests, and informal, formative, and summative assessments.

The next step in the planning is to determine which policies and practices would yield the best student learning outcomes (Willis, 2002). This is no small matter as with every new initiative, there is no shortage of materials or resources that purport to be related to that initiative. The CCSS are no different. There are a plethora of companies and sellers that market materials with CCSS stamps on it (Rubinstein, 2013). One helpful way to decide what is trustworthy research is to search believable sources such as ERIC, journal storage, journals of the American Educational Research Association, especially the Review of Educational Research and Review of Research in Education. These will help to match instructional practices and policies that fit with the desired student learning outcomes.

Needed Organizational Support is the third step of Guskey's (2014) professional 
learning planning. Here is the crux of the planning success. Without clear leadership support, time, instructional materials, resources, and efficient technology, it is impossible for teachers to be effective and the for the change implementation to be successful. Additionally, it is important for teachers to receive feedback on the results (Goodwin \& Miller, 2012). Students' learning success is the goal. Through the process of implementation, there must be regular feedback so the teachers can know that their efforts are paying off. Feedback is the battery to the implementation step.

Professional Development helps to "create the conditions that support the ongoing learning of the most important resource in any school or district — the professionals who work there" (Dufour, 2014, p 35). Additionally, Judith Warren Little (2006), the Carol Liu professor of education policy in the Graduate School of Education at the University of California-Berkeley, has researched the policies and practices of Professional Development and has confirmed that the professional learning community process affords the best environment for teachers to experience powerful Professional Development. In turn, that environment build staff endurance to function as efficient members in that professional learning context.

According to Dufour (2014), professional learning development must follow a clear and concise path according to research today.

1. It must be "ongoing, with sustained, rather than episodic and fragmented focus" (Dufour, 2014, p. 30).

2. It must be collective rather than individualistic.

3. It must be job embedded with teachers learning as they engage in their daily work. 
4. It must be result oriented with activities directly linked to higher levels of student learning.

Changing teachers practice is very important if they are to meet the demands of the CCSS (Birman, Desimore, Porter, \& Garet, 2000). The best place for teachers to grow and change their practices (Berkowicz, \& Myers, 2013) in order to affect student learning is through Professional Development. It is not a task that is facile, to be sure, but school districts all over must grapple with the challenges of elevating teachers' practices through learning. "Professional learning is the key to improving instruction" (Scherer, 2014, p. 7).

Allison Gulamhussein (2013), the author of the research report: Teaching the Teacher: Effective Professional Development in an Era of High Stakes Accountability, looks at the research and extracts five principles that undergird effective Professional Development.

The first principle is the duration of Professional Development. The time allotted must be significant and ongoing. Teachers must have enough time to learn new strategies and to wrestle with implementation issues. They may need as many as 50 hours of practice to support their mastery of a new teaching strategy.

The second principle deals with the issue of implementation. Teachers must receive support during implementation. Merely describing a new skill to teachers only accounts to $10 \%$ of teachers transferring the skills into their teaching practice. On the other hand, when teachers are coached through the uncertain phase of implementation, $95 \%$ of them can transfer the skill into their teaching.

The third principle has to do with the initiation of the change. Teachers' initial exposure to a concept should not be passive. It should give the teacher the opportunity to 
engage in learning through various approaches such as role playing, classroom observations and live modeling in order for them to have clarity about the new practice.

The fourth principle underlines the importance of modeling. Modeling is highly effective. Teachers will best understand the how's and why's of implementation when an expert model the new practice for them.

The last principle regards the context of delivery. Professional Development is best delivered in the context of the teacher's subject area or grade level. To offer training on topics that are generic is useless in the context of teacher development and student learning improvement.

The best way to structure a professional learning community in a school is to have small teams of educators learning and collaborating together (Goodwin 2014; Murphy, 1992). Groups should be small enough to not become overwhelming and their members should typically teach the same subject (Dufour, 2014). According to Goodwin (2014, p. 80), "small teams are more efficient and less frustrating."

Joyce and Showers (2002) reinforce the importance of developing professional learning groups that are small enough to be effective. Based on research and experience, they identify four common components of professional training:

1. Presentation of new skills and methods.

2. Demonstration of new skills and teaching methods.

3. Opportunities to practice the new skills and methods.

4. Peer coaching on the new skills and methods.

They have found that the first three components were responsible in the augmentation of teacher's knowledge about classroom instruction. However, the peer 
coaching component - when it occurred in small, reciprocal groups - supported $95 \%$ of teachers and made it possible for them to transfer new knowledge into their teaching practice (Goodwin, 2014).

\section{Whole Faculty Study Group}

Murphy $(1992,1995)$ advocates the whole faculty study group approach to Professional Development. It is a way for a whole school or system to implement an innovation at the same time for the same purpose. This approach creates a learning environment where teachers participate, practice, give feedback, and coach each other. It creates a subculture of shared beliefs and values for teachers to practice.

Whole school study groups share a common set of components. The group must be comprised of four to six people; the focus must be the implementation of an innovation; the innovation must focus on increased student achievement; the group must meet during a regular schedule and during a regular school day; there must be a written agenda; leadership must be predetermined albeit in a rotated basis; and there must be a $\log$ to document the meetings.

Additionally, there must be assignments and participation report to document progress; administration must participate; training must include modeling, demonstration, practice, feedback, and coaching; the environment must be risk free and collaborative; there must be an established connection between the initial training and follow up activities; the meeting must be regular and follow a pattern; there must be reflection on student learning and action plans toward continued progress.

The whole faculty study groups of four to six people meet regularly to focus on teaching and learning. This approach follows five basic guiding principles: 
1. Students are first.

2. Everyone participates.

3. Leadership is shared.

4. Responsibility is equal.

5. The work is public (Murphy, 1995).

Whole faculty study groups are successful when participants follow these steps: discussion of theory or rationale of the innovation, demonstrations of the innovation, practice and feedback, and coaching.

\section{Fullan's Change Process and the Florida Conference Adoption of the CCSS}

The Florida Conference has a long-standing practice of training and developing their educators. They have established study groups, a mentoring and coaching program, and summer in-service classes. The classes are sometimes voluntary for teachers' growth or recertification but at times, the conference assigns training or mentors to teachers based on their Professional Development needs. During the process of adopting the CCSS, the conference planned and delivered training to its teachers. What follows here represents a timeline or sequence of events leading to the adoption of the CCSS.

During the early part of December 2011, the NAD Education Advisory recommended that the Seventh-day Adventist school system adopt the Go Math! for Grades K-6 and Big Ideas for Grades 6-8 curriculum for the school year 2012-2013. The NAD Elementary Math Summer Committee endorsed or made the same recommendation in early January of 2012.

The Southern Union responded to the adoption of Go Math! and invited 
representatives of the publisher, Houghton Mifflin Harcourt, to present to the Southern Union Education Council in March of 2012. I was one of the school leaders who were included in that training in March of 2012 in Jacksonville, Florida. There, for the first time, I heard of the CCSS and the eight tenets that undergird them. They were the CCSS for Mathematical practice (Burns, 2012-2013):

1. Make sense of problems and persevere in solving them.

2. Reason abstractly and quantitatively.

3. Construct viable arguments and critique the reasoning of others.

4. Model with Mathematics.

5. Use appropriate tools strategically.

6. Attend to precision.

7. Look for and make use of structure.

8. Look for and express regularity in repeated reasoning.

The new curriculum would help teachers to use these eight practices in their Mathematics instruction. There at the meeting, the curriculum was introduced and we were charged to go back and introduce the program to our schools. We were also given the list of materials and the negotiated costs between the publishers and the Southern Union, which each school would be responsible to purchase.

From the NAD to the Southern Union, now it was our conference's turn to introduce the new curriculum to the teaching body. Plans began in April 2012 to divide the leaders who had been recently introduced to the new program to spread out to the four areas of the Florida Conference. The purpose of this training was to introduce the new curriculum and to familiarize the teachers to the Mathematics books which they would 
soon use. In fact, the training was called Math Book Training. One group was led by a teacher in Naples. She led the small schools and upper grades teachers within driving distance of Naples. In the South, teachers met at Greater Miami Adventist Academy with another presenter; the central part of our conference is home to the biggest schools and the meeting was held at Forest Lake Education Center (FLEC) where I and a colleague from Orlando Junior Academy presented. Finally, in the Western part of our conference, the meeting was held in Tampa Adventist Academy and was presented by a teacher representative.

My colleague and I, as we presented the rationale for this new curriculum, referred to the CCSS and explained that this new program would help us to meet the CCSS. It was not clear how many in the audience had ever heard of the CCSS but we forged ahead just as the publishers had done for us at the initial training. There was much to present, to learn, and to plan in order for this program to start at the beginning of the school year 2012-2013.

As planned, during the summer of 2012, I purchased the new materials for Go Math! Our school had decided to start with first grade through fifth because we are one of the biggest schools in North America and, therefore, adoption of any kind is a very big undertaking. The adoption for the Kindergarten class would happen the following summer in preparation of the 2013-2014 school year. In the meantime, we purchased just enough Kindergarten materials to conduct a study group during the 2012-2013 school year so that the four Kindergarten teachers would be ready for the adoption.

I communicated with the publishers and received the materials before our new budget went into effect for July 2012 which is the new fiscal year. The materials would 
arrive on time for our teachers to be familiar with them and to plan ahead. We also purchased the online resources which consisted of all the print materials in addition to the educational games.

During the school year 2012-2013, our school conducted study groups for Grades $1-5$ in order to support each other through the adoption process. The materials were different from the previous Mathematics program — the Singapore math, but the teachers and I were thankful for the abundance of print and online materials and the manipulatives that came with them.

During the school year 2013-2014, I was once again invited to Atlanta, Georgia to attend a one-day meeting to review the Go Math! program with the publisherparticularly the online resources. When I returned, I met with my staff to check the latest review against our current practice. Any adjustments or any new cues that I had amassed in the training (the program called Soar to Success was problematic to many of the users), we incorporated into our study group.

According to Fullan's change process (2007), there must be an initiation of the change. The Southern Union initiated the new curriculum as part of our adoption of the CCSS. What was missing was the declarative statement of Joyce and Showers (2002) that would declare to the people that the CCSS had been adopted and that would rally them to one group and one voice. The need for a declarative statement became very clear during a different meeting.

During the latter part of the school year 2013-2014, our conference invited me to a meeting to invite us to join with an organization-Success Makers — which deals with parent engagement and the Step-Up scholarship which is a grant given to students who 
qualify financially to choose and attend schools they would otherwise be unable to afford. There, as we chatted, a principal from another school lamented the fact that we (the Adventist school system) should have come up with the idea of parental engagement on our own instead of partnering with an organization. The discussion turned to the CCSS at which time the principal shared the fear that the state is taking over and soon we will not be able to teach the Bible because we are all "mixed up with the Common Core."

I thought about that statement and wondered how much that individual knew about the CCSS. I was not worried about agreement or disagreement with the CCSS. I was concerned about the proper knowledge about a particular change that allows individuals to take a stand, to question, to accept, or to refute. There did not appear to be enough information about the CCSS to allow such deliberations.

The second phase of Fullan's stage is the implementation. This phase is the meat of the change process for through the use of the change; it cements it into longevity or kills it. Our teachers in the Florida Conference implemented Go Math! as a mandate, but if the purpose of implementation was to bring about knowledge and lasting change, some important questions must be posed. Most importantly, we must ask: How are teachers implementing the CCSS in the classroom?

The CCSS are different from the standards that were used previously. The different shifts in ELA and Mathematics call for teachers to teach differently than they were previously. What are the teachers' perceptions regarding the adequacy of their Professional Development to support the implementation of the CCSS? How are teachers implementing the CCSS in the classroom in terms of planning, teaching, and assessment? What are teachers' perceptions regarding the impact of the CCSS on student learning? 


\section{Summary}

The literature provided a framework of best practices for this study in order to comprehend the foundation and information upon which I built the study. The main ideas were the CCSS and Professional Development. It was important for me to share the facts regarding the CCSS and the research behind the process of change and Professional Development. Hall and Hord's (2011) principles of change worked as guiding lights for change implementers so that the process of leading and learning through change does not become an isolated and lonely enterprise. Fullan's (1993, 2002, 2007) steps and methods to change also guided the concept of change through a clear and logical path from the beginning of an initiative to the point where it becomes a part of the institution. Training is vital throughout the learning process and Joyce and Showers (2002) provided just how to present, demonstrate, and practice with educators in order to support them through changes. Murphy (1995), Guskey (2000, 2014), and Dufour (2004, 2014) provided guidelines for establishing a professional learning community and whole faculty study groups. The inclusion of Understanding by Design through the use of Backward Design and planning (Guskey, 2014; McTighe \& Thomas, 2003; McTighe \& Wiggins, 2004; Wiggins \& McTighe, 2005) was to share with the reader that in any learning-whether educators or students, it is important to begin the planning with the end goals in mind. In training for the adoption of the CCSS, the backward design would have helped to provide a clear picture ahead of time of the results that are desired, the evidences that are acceptable to show that the results are met, and finally the training activities that would elicit such evidences that showed that the teachers have met the desired results of implementing the CCSS in the classroom. Finally, working on change without addressing 
the culture is like planting without tilling the soil. Culture plays a vital role in how people respond to change and change leaders must understand and purposefully address and in certain cases modify the culture in which they want change to take root.

All of these are necessary for change leaders and implementers to ensure that all teachers are well-trained and our students receive the highest quality of education resulting from the delivery of sound practices. 


\section{CHAPTER 3}

\section{METHODOLOGY}

\section{Study Focus}

This qualitative case study focused on educators who teach in the Florida Conference of Seventh-day Adventists and their perceptions regarding the adequacy of the Professional Development to support the implementation of CCSS. I chose this area to study because it is part of my work and because its results will provide direct information to conference educational leaders regarding the CCSS, their adoption, and the need for Professional Development in the process of change.

The following questions guided the study:

1. What are the teachers' perceptions regarding the adequacy of their Professional Development to support the implementation of the CCSS?

2. How are teachers implementing the CCSS in the classroom in terms of planning, teaching, and assessing?

3. What are teachers' perceptions regarding the impact of the CCSS on student learning?

\section{Participants}

\section{Population}

This study drew from the population of the educators who work in the Florida 
Conference of Seventh-day Adventists. Florida Conference, with its headquarters situated in Altamonte Springs, Florida, is part of the worldwide church of Seventh-day Adventists. The world church, a mainstream Protestant, Bible-believing body with a membership of more than 18 million people, is divided into 13 divisions: South America, South Pacific, Southern Africa-Indian Ocean, Southern Asia, Southern Asia Pacific, Trans-European, West Central Africa, and the NAD.

The NAD is comprised of: Bermuda, Canada, Federated State of Micronesia, the French possession of St. Pierre and Miguelon, Guam, Johnston Island, Marshall Islands, Midway Island, Northern Mariana Islands, Palau, and the United States of America. The Division has about 1.1 million members and operates about 850 elementary and secondary schools and 13 colleges. The Division is divided into nine smaller bodies called Unions: Atlantic, Columbia, Lake, Mid America, North Pacific, Pacific, Southern, and Southwestern.

Each union is divided into conferences. The Florida Conference is part of the Southern Union which is divided into eight conferences: Carolina, Florida, Georgia Cumberland, Gulf States, Kentucky-Tennessee, South Atlantic, Southeastern, and South Central. These eight conferences include the states of: Alabama, Florida, Georgia, Kentucky, Mississippi, North Carolina, South Carolina, and Tennessee.

As described above, the Florida Conference is a part of the hierarchical levels within the worldwide Adventist church. It is an unincorporated, non-profit organization that governs a group of churches. Its main emphases are school operation, evangelism and the nurturing of its constituents. The Florida Conference was organized in 1893. It includes the state of Florida except the following counties which belong to the Gulf 
States Conference: Bay, Calhoun, Escambia, Gulf, Holmes, Jackson, Okaloosa, Santa Rosa, Walton, and Washington. The conference operates 206 churches, 56 companies, and 33 mission groups.

One of the departments in the Florida Conference is the Department of Education. It directs about thirty elementary schools with about 205 teachers in the Grades $\mathrm{K}-8$, four high schools (academies), and 14 child-care centers. The schools are divided into zones by north, south, central, and west Florida. Currently, the Florida Conference Department of Education is directed by a Vice President of Education and four associate superintendents and their support staff. These individuals share the work of overseeing schools, supervising educators, evaluating and recommending/mandating curriculum and educational processes, recruiting and supporting teachers and staff, and planning and delivering conference-wide training. This list of duties is not exhaustive.

The Florida Conference manages about four K-12 schools, three K-10 schools, $23 \mathrm{~K}-8$ schools, and five Early Learning Centers. Participants for this study were chosen at random from a list of all the $\mathrm{K}-8$ schools except one. The Forest Lake Education Center, the 660-student elementary school, which is among the largest in the NAD, was eliminated due to its dissimilarity with the majority of Adventist schools. The school's size, the number of the support staff, and the level of financial resources might add an unrealistic slant to the study. Additionally, I have worked at the school for the last eleven years and exclusion of the school will erase any potential conflict of interest among the participants and myself. Some participants were from $\mathrm{K}-10$ schools because of their middle school teaching designation. 


\section{Criteria for Participation}

Purposive sampling (Creswell, 2014) allowed for participants who would provide the best information for the study. It was important that participants have firsthand knowledge about the case under study. Consequently, participants were purposely chosen among two different types of teachers from the Florida Conference: ELA and Mathematics teachers and two levels of teaching: Primary (Grades K-5) and Intermediate (Grades 6-8) after permission was requested and received (see Appendices A \& B). All participants were educators who worked in the Florida Conference since the inception of the CCSS into the organization in 2012.

\section{Procedures in Data Collection}

During the fall of 2016, I constructed a list of the educators who worked in the conference since the adoption of the CCSS. The names, schools, and grades were submitted to me by the Florida Conference. Next, I wrote each name on a small card with identifiers such as: name, school, grade (s) taught, primary or intermediate. The identifiers were on one side except for the name which was on the other side by itself. Then, I divided the names into two piles: Primary (Grades K-5) and Intermediate (Grades 6-8). Teachers who taught Grades 5-8 or 4-8, or even 1-8, were placed into the Intermediate folder but would be used as primary if needed. I placed all the cards facing the way that would allow me to pull them without viewing the participant's name. Then I shuffled them as I would a deck of cards before placing them in their respective envelope. Finally, I began the process of choosing the cards. The goal was to select eight teachers for the study.

I placed the primary pile into an envelope labeled "Primary" and the intermediate 
pile into an envelope labeled "Intermediate." I alternated between primary and intermediate to pull and label the cards by the order which they were picked. For example, the first card I picked from the Intermediate envelope was labeled "study participant intermediate 1st picked or SPI-1.” This became the code for each participant: the prefix study participant with the teaching level primary or intermediate, and finally, the order in which they were picked.

Now I had the following:

Study participant intermediate (SPI)-1

Study participant primary (SPP)-2

SPI-3

SPP-4

SPI-5

SPP-6

SPI-7

SPP-8

\section{Invitation and Responses}

After selecting potential participants for the study, I emailed the educators to invite them to participate in the study (see Appendix C). I asked them to reply as soon as possible. I received the following responses:

SPI-1: Did not respond even after the second and last reminder.

SPP-2: Responded and declined with regrets.

SPI-3, SPP-4, and SPI-5: Responded and agreed to participate.

SPP-6 and SPI-7: Responded and declined with regrets. 
SPP-8: Did not respond.

After the first drawing and emails, I had three participants: Two Intermediate teachers and one primary teacher.

\section{The Second Drawing}

With three participants, I decided to draw five more cards in the hope of gathering a total of eight participants. I began with the primary list since I had less participants (albeit, just one less than intermediate) from that list. This new batch would comprise of:

SPP-9 (to replace SPP-2)

SPI-10 (to replace SPI-1)

SPP-11(to replace SPP-6)

SPI-12 (to replace SPI-7)

SPP-13(to replace SPP-8)

I emailed and invited this new group of teachers. I received the following responses:

SPP-9: Did not respond.

SPI-10: Responded and agreed to participate at the same time the very first picked (SPI-1) responded and agreed. These two would go on later to be the first and second interviews that I conducted for this study.

SPP-11: Responded and agreed to participate.

SPI-12: Responded and agreed to participate but stopped responding when asked for an interview date.

SPP-13: Responded and declined with regrets.

Most regrets cited the lack of time, the difficulty in workload, and struggles with 
loved ones who are sick. Two teachers called to wish me the best in the study and shared that they know me as a great worker in the field of education.

The second batch of respondents yielded the following:

SPI-10

SPP-11

In addition to the positive response from SPI- 1, now I had three to add from the previous batch. I counted six participants. In examining the group, the following attributes came to light:

Based on the list that the Florida Conference submitted and my prior knowledge of the teachers, I deducted that among the respondents, there were:

Four coded as intermediate and two as primary. I converted one intermediate (SPI-10) into a primary because that teacher met both criteria. Now I had three of each.

With three primary and three intermediate educators, I inspected for other characteristics and the results yielded the following:

There were various grades:

SPI-1: Grades 5-8

SPI-3: Grades 6-8

SPP-4: Grades 3-4

SPI-5: Grades 6-9

SPI-10: Grades NR (used as primary) SPP-10

SPP-11: Grades 4-5

There were various demographics:

Two White Males 
One White Female

Two African-American Females

One Hispanic Male

The participants' schools were located in various regions across the conference and were of various sizes though I had not yet determined the actual size until the interviews.

\section{Sample Size}

From the information listed above, I made the decision to move on with the interviews using six respondents instead of searching for two more from the list of teachers who were in the envelopes. The two drawings, the emails, and the responses had taken the better part of August and September 2016, and I decided to begin the interviews starting the month of October.

\section{Data Sources}

This study was qualitative in nature. When the data are conveyed or derived from words, the study is qualitative whereas if the data is presented by numbers, the study would be labeled as quantitative. Qualitative data comprise of "direct quotations from people about their experiences, opinions, feelings, and knowledge. Data from observations consist of detailed descriptions of people's activities, behaviors, actions, and the full range of interpersonal interactions and organizational processes that are part of observable human experience" (Patton, 2015, p. 14).

The data sources for this study consisted of six interviews with educators - three primary teachers and three intermediate teachers chosen at random from a stack of cards 
labeled "Primary teachers" and "Intermediate teachers." Two observations were done to follow up. Those two teachers were chosen because of their location and my access to them. However, an additional benefit was that their subject matters differed from each other which allowed for better clarification of the data in ELA and in Mathematics (see Table 1).

The six participants who were randomly selected were not total strangers to me. At one time or another and to varying degrees, we have interfaced with each other in Conference training or meeting, school visitation, or school evaluation. One of the participants was a part of a summer training that I led a few years ago. During the interview, one participant stopped to share their happiness that I was this far on my dissertation and willingness to help me wherever I needed. Another participant, perhaps knowing my work and background with the conference in literacy, mentioned that: "I know you are an expert in this [ELA]." Still another started a couple of responses with: "I don't know if you're aware" or "I'm sure you know."

While this familiarity established ease, confidence, and a feeling of camaraderie among participants, it was important for me to maintain the role of researcher and avoid the role of teacher mentor. For example, one participant was hesitant on one question and wanted my opinion and feedback on her response. I focused the participant on the question and we continued. This familiarity gave ease to the flow of the conversation between me and the participants as we were not strangers but it did not distract from the study.

Interviews

Interviews are one of the ways to obtain data for a qualitative study. For many 
Table 1

\section{Participants}

\begin{tabular}{lcccccc}
\hline Code Name & Current Grade & \# of Years Teaching & \# of Teachers at School & Age Range & Gender & Ethnicity \\
\hline SPI-1 & $5-8$ & 37 & 5 & $40-50$ & F & AA \\
SPI-3 & $6-8$ & 26 & 16 & $40-50$ & F & W \\
SPP-4 & $3-4$ & 5 & $40-40$ & F & AA \\
SPI-5 & $6-9$ & 25 & N/R & $40-50$ & N/R & M \\
SPP-10 & N/R & 27 & N/R & 50-60 & M & W \\
SPP-11 & $4-5$ & 16 & 10 & & W \\
\hline
\end{tabular}

SPP-\# =Study Participant Primary - \# Randomly Picked SPP-\# =Study Participant Intermediate - \# Randomly Picked $\mathrm{N} / \mathrm{R}=$ Not Reported 
centuries, interviewing has served as a means to collect information. In qualitative study, interviews are described as "a conversation with a purpose" (Merriam \& Tisdell, 2016; Patton, 2002; Smith, Flowers, \& Larkin, 2009). "Some and occasionally all of the data are collected through interviews ... and depending on the topic, interviewing is sometimes the only way to get data" (Merriam \& Tisdell, 2016, pp. 108-109). Interviews allow the participants to share their lives, their thoughts, stories, and perceptions. They also provide the researcher the necessary information for the study and valuable insights into the participants' world and perspective. Interviews can produce very rich data for analysis in a study when the participants have the chance to tell their stories, to reflect and to speak at length, and to share their concerns freely (Smith et al., 2009).

For this study, I used a semi-structured format of interviewing. This is the preferred means of collecting data on a one-to-one basis because it is easier to manage the interviews, to create rapport with the participants and give them space to communicate, consider, and conceive ideas and concerns (Merriam \& Tisdell, 2016; Patton, 2002; Smith et al., 2009). The schedule in the semi-structured format is simply a guide (Patton, 2002). It can change once the interview is under way and the order may vary from one participant to the next. Semi-structured interviews allow for a more natural, conversational tone between the interviewer and the participant as opposed to the rigid linear process of structured interviews. That flexibility allows the parties to develop rapport and empathy, which are very useful for the interview and increases the likelihood of obtaining rich, relevant and interesting data (Smith et al., 2009).

For the semi-structured interviews in this study, I prepared the study questions ahead of time that targeted the information I hoped to garner based on my research 
questions. The order of the interview questions followed the flow that, in my professional judgement and with feedback from my advisor, made the most sense for optimal data collection and felt more natural for my communication style. The semi-structured interview protocol prepared me in advance to conduct the interviews. Additionally, I was able to share the core questions with the participants in advance to enable them to begin their personal reflection before the interviews occurred.

Questions in a qualitative study are very important. In the semi-structured interview, the researcher prepares a set of questions - a guide or schedule ahead of time to help facilitate the flow and order of the interview. It is imperative that the researcher asks those questions that would produce the most detailed and in-depth responses in order to obtain rich and relevant data.

According to Merriam and Tisdell (2016), "Good questions are those that are open-ended and yield descriptive data ... the more detailed and descriptive the data, the better" (p. 120). Open-ended questions are those that allow the participants to share, extend, and expand on their responses instead of providing one short answer in response to close-ended questions. Good questions invite the telling of stories, details, recalls, and recounts: "Tell me a time when ... give me an example of . . tell me more about that ... what was it like for you when ...?” (Patton, 2002, p. 120).

Patton (2015) suggests six types of questions that are beneficial to a qualitative study:

1. Those questions that ask about experiences and behaviors require that the participants talk about what they did or do now, about their acts, behaviors, or activities. 
2. Opinions and values questions inquire about the participants' opinions and beliefs on specific matters.

3. Feelings questions allow the participants to share their feelings. Adjectives such as these might be expected: angry, disappointed, fearful, joyful, brave, etc.

4. Knowledge questions ask participants to relate facts about the topic.

5. Sensory questions are similar to the questions about experience, but differ on their focus on the senses. The participants are asked to relay what they heard, saw, touched, smelled, etc.

6. The final set of questions are those asking about background or demographics. To the extent it is valuable and necessary to the study, the researcher may ask the participants' age, sex, number of years on the job, income and educational levels, etc.

Smith et al. (2009) suggest seven types of questions that have the greatest possibility to offer detailed information:

1. Descriptive. Please tell me what you do at your job.

2. Narrative. Please tell me how you got your job

3. Structural. What are the steps in doing this activity at your job??

4. Contrast. Describe a good and a bad day at your job.

5. Evaluative. How do you feel about ... ?

6. Circular. What do you think your principal thinks about how you teach?

7. Comparative. How do you think it would be if you taught at a different school?

In addition to good questions, prompts and probes support the participants in telling their responses. Prompts encourage participants to give more details (Can you say 
more about that?) while probes ask for clarification (What do you mean by 'outrageous'?) (Smith et al., 2009).

As much as it is necessary to pose good questions, there are also questions that the researcher should avoid; those that have multiple questions in one, those that lead the participants, and those that incite only yes or no responses (Merriam \& Tisdell, 2016). Smith et al. (2009) also offer some questions to avoid:

1. Over-empathic. I can imagine that teaching those kids is quite hard. Is that correct?

2. Manipulative. You said teaching those kids was tough. Is it even more difficult than that?

3. Leading. So, I don't guess you would say that teaching here is worth your time?

4. Closed. And you've been teaching here for ten years now?

\section{School and Classroom Observation}

Observation is another way to gather data in a qualitative study. "It makes it possible to record behavior as it is happening" (Merriam \& Tisdell, 2016, p. 139). It is an important source of data gathering as it allows the researcher to obtain a firsthand account of situations and the places and people in a study. When used with interviewing and document analysis, observation provides a clear picture for the interpretation of the phenomenon under study.

As in interviewing, the degree of structure varies from more to less structured. For this study, a less structured format was used and I observed activities that would enrich my analysis of the data obtained from the interviews. These constituted my field notes 
which were highly descriptive (Merriam \& Tisdell, 2016). They included information about the time, place, and purpose of the observation and "included descriptions, direct quotations, and observer's comments" (p. 161).

\section{Documents and Artifacts}

Documents and artifacts are the final sources of data in this study. When combined with interviews and observations, they may "help the researcher to uncover meaning, develop understanding, and discover insights relevant to the research problem" (Merriam \& Tisdell, 2016, p. 189). Artifacts are three-dimensional physical objects in the environment that may provide information to the researcher regarding meaningful communication to the participants or the setting. Together with written, visual, and digital materials, they form the category of documents, which "can tell the researchers about the inner meaning of everyday events" (p. 166). According to Patton (2002), "documents provide the [researcher] with information about many things that cannot be observed ... things that happen before the [research] took place" (p. 293).

My research questions, as well as "educated hunches and emerging findings" (Merriam \& Tisdell, 2016, p. 175), guided my data collection from documents. I followed a systematic process as the research instrument, using my knowledge of the literature and personal experiences to be skillful, intuitive, and open-minded in the search for and interpretation of data. While the setting may have offered valuable data by accident, the materials I requested from the participants were lesson plans, student assignments, and items - pictures or anchor charts on display in the classrooms. These added valuable information to the interviews and the observations in addition to enabling triangulation of results (see Triangulation below). 


\section{Strategies for Validating Findings}

Researcher as Instrument

It is proper to say that the work cannot be separated from the worker. Consequently, this qualitative case study was very close to me. For many years, I have been one of the classroom teachers who have had to translate initiatives into practice. Now, as a Vice Principal of one of the largest Adventist schools - FLEC, I am the main person charged with the task of leading the staff through changes. I cannot separate this research from myself, as the focus of the study was also the focus of my work. According to Merriam and Tisdell (2016), one of the characteristics of all qualitative research is that the researcher serves as the primary instrument for data collection and analysis. This means that "a human being is the instrumentation of the qualitative methods, a real, live, person makes observations, takes field notes, asks and interviews questions, and interprets responses" (Patton, 2002, p. 64).

As an instrument, the researcher must have a voice that is credible and trustworthy. The competence and rigor of the researcher are important to the credibility of the qualitative study. "Evaluators aim for balance, fairness and completeness" (Patton, 2002, p. 51) in a study which shows professional integrity and respect for the participants and those to whom they report.

\section{Researcher as Instrument: Benefits}

The main goal of qualitative research is to understand (Merriam \& Tisdell, 2016) the world as it unfolds and to be true to its complexities, wonders, and the many emerging perspectives and to be balanced and candid in the reporting of evidences that are both confirmatory and disconfirming (Patton, 2002). With that goal in mind, the 
researcher would be the best person to man that responsibility. The human instrument is able to be present throughout the study: to collect and analyze data; to expand understanding through nonverbal and verbal communication; to process and clarify information immediately; and to check with participants on the accuracy of interpretation (Merriam \& Tisdell, 2016).

\section{Researcher as Instrument: Disadvantages}

There have been controversies regarding the use of the qualitative method. The arguments are rooted from the "long standing debate in science over how best to study and understand the world" (Patton, 2002, p. 571). Some researchers believe that objectivity is the strength of the scientific method and others, like Patton (2002), purport that "both objectivity and subjectivity have become such debated terms that neither provides useful guidance" (p. 51).

The researcher as the instrument in the qualitative process must guard against bias and personal agenda so that the work might be respected and trusted. There must not be a "quest to set out to prove a particular perspective or manipulate the data to arrive at predisposed truths" (Patton, 2002, p. 51). The researcher must identify and monitor any shortcomings or bias that may affect the study and "monitor them in the light of the researcher's own interests and to make clear how they may be shaping the collection and interpretation of data" (Merriam \& Tisdell, 2016, p. 16).

\section{Reflexivity}

Experience is not the best teacher. Rather, we learn best when we take the time to reflect on our experiences (Dewey, 1916). The term reflexivity is used to emphasize the 
need for evaluators to be self-aware throughout the process.

Being reflexive involves self-questioning and self-understanding, to be reflexive then is to undertake an ongoing examination of what I know and how I know it. It is to have an ongoing conversation about experience while simultaneously living in the moment. (Hertz, 1997, p. viii, as cited by Patton, 2002, p. 64-65)

Self-awareness is a desired trait for it allows the researcher to look within, to monitor assumptions, and to explicate any bias or understanding that may influence the conduct and conclusions of the research (Merriam \& Tisdell, 2016). Reflexivity in research reminds the researcher to pay close attention to the various thoughts and voices and their roots - whether they are cultural, social, or political. It demands that examiners be self-reflective and have a high degree of self-knowledge in order to be willing to consider how who they are affects what they are able to observe, hear, and understand in the field as observers and analysis (Patton, 2002).

The fact that I have been a classroom teacher and work as a school administrator gave me insight and provided interest into the study and the people I interviewed. However, that did not take away from my most solemn duty as a researcher to be reflective about my own voice and perspective and to use a credible voice and procedures to convey professionalism, authenticity, and trustworthiness in my study (Patton, 2002). Many educators work, study, and research in their field in order to add insight, to improve processes and structures, or to support other educators in the profession. The work of educators is a team effort because it takes a team to do this important work (Sterrett, 2011).

\section{Data Analysis}

General Approach to Analysis

Data analysis is the process of making meaning or sense out of the data. It 
involves reducing, consolidating, and interpreting what people said and what the researcher saw or heard. The primary purpose of the data analysis is to find answers to the research questions (Merriam \& Tisdell, 2016). For this study, the following research questions guided the collection and analysis of the data.

1. What are teachers' perceptions regarding the adequacy of their Professional Development to support the implementation of the CCSS?

2. How are teachers implementing the CCSS in the classroom in terms of planning, teaching, and assessing?

3. What are teachers' perceptions regarding the impact of the CCSS on student learning?

The data collection process in this qualitative study through interviews, observation, and documents and artifacts gathering went hand in hand with the analysis of the interview scripts, the observation field notes, and the document collection. Analysis and collection are simultaneous processes (Charmaz, 2014; Glaser \& Strauss, 2006; Merriam \& Tisdale, 2016). Once a researcher begins the process of analyzing, it is ongoing until the results are written and presented.

It is very important that researchers begin the process of analysis early in the process of collection. Emerging findings can help shape further data collection, as they indicate areas where data needed to answer the research questions may be a bit thin. Also, the task of analysis, if left undone for a long time, may become daunting and paralyzing to the researcher. After the first interview, observation, and documents/artifacts collection, I reviewed the purpose of my study, read the data I collected repeatedly, and then made notes on the margin and comments about the data. I also kept a journal where I 
shared my reflection, hunches, ideas, and themes to compare with the second set of interviews and so on.

\section{Ensuring High Quality Results}

Threats to Credibility of Results

Qualitative study, while a worthwhile endeavor, is also a human enterprise that is subject to frailty and error. Methods of data collection such as interviews, observations, and documents analysis are not without their limitations. Data from interviews might be limited by distorted responses due to the participants' bias, anger, grudges, disappointments, etc.; participants may fail to recall or recall inaccurately; or participants may respond in self-interested ways (Patton, 2002)

Observations might also be limited due to the possibility that the researcher may unknowingly influence the environment in some undefinable ways. For example, the act of being observed may cause school staff or participants to behave differently than usual. This is referred to as the Hawthorn Effect (Wickstrom \& Bendix, 2000), which explains the possibility of positive results in the interventions for studies because the behavior of the participants may change as they know that they are being observed and they may be more compliant in abeyance to what they think the researcher would want. In addition, observation is an external process that does not afford a look within the participants' thoughts and feelings (Patton, 2002).

Documents and records might be inaccurate, fragmentary, inauthentic, or incomplete especially because they are "usually produced for reasons other than research" (Merriam \& Tisdell, 2016, p. 183). Moreover, the information that documents 
offer might not be meaningful to the researcher or relevant to the study or fit within its framework (Patton, 2002).

\section{Strengthening Credibility with Triangulation}

Even with their potential individual limitations, when combined together, interviews, observations, documents, and artifacts can produce data that is "consistent and dependable, as well as data that is most congruent with reality as understood by the participants" (Patton, 2002, p. 307). This method of using multiple types of data collection is called triangulation. It allows for checks and balances in the data collection and analysis processes. When using triangulation, interviews serve as a way to go beyond the surface and to delve into the participants' thoughts and feelings. Interviews allow the participants and the researcher to dialogue, speak, question, share, and explain. Most importantly, interviews allow the researcher to listen.

Observations allow the researcher to cross check what was said in the interviews and to gain better understanding of the data. Documents, records, and artifacts give the researcher an inside look and their analysis may incite further questions and clarification for the study (Patton, 2002). The researcher is able to obtain information that cannot be observed or gleaned from an interview because the documents or artifacts are often in existence prior to or independent of the research. Using multiple data sources helps to eliminate possible bias that may come from using just one source.

Using different participants served also to strengthen the data in the study. Instead of interviewing just one person and allow that one voice to speak, several participants were chosen in order to obtain useful and credible information from a purposeful sampling of participants. 


\section{Ethical Conduct of Research}

I am forever a teacher and most especially, I am a Seventh-day Adventist

Christian educator. With that, I bring to my research the worldview of a Christian theist who views the world through the lens of one who believes in a Supreme, Omniscient, and Sovereign God who is very good (Sire, 2009; Thomas, 2013). I believe that in dealing with others, I must exercise a lot of care and compassion. As an educator, I must reflect in my actions and attitude that people matter. Just as "Good teaching comes from the identity and integrity of the teacher" (Ornstein, Pajak, \& Ornstein, 2011, p. 63), the integrity of the researcher is tightly woven to her identity as an honest and trustworthy individual.

I bring to the research the words of Sire (2009). "So, ethics, while very much a human domain, is ultimately the business of God. We are not the measure of morality. God is" (p. 43). Those words kept me centered and focused on the main reason which was at the heart of this study - to make a difference in my profession and my colleagues. According to Merriam and Tisdell (2016), "Actual ethical practice comes down to the individual researcher's own value and ethics" (p. 261). As a Christian educator, my ethics are derived from a God who is true and just. While completing this study will help me in a tangible way to complete my doctorate, this fact is not the fire that ignited my passion. My ultimate purpose was to be of service to the teachers and students I serve. As a leader, I question and reflect on my educational practices. Am I all that I can be? Am I doing all that I can do? Do I love and care enough for the people with whom I serve? I question my commitment, my conviction, and motives for my actions and my thoughts. Therefore, for this research, I wanted it to be of benefit to my profession and my colleagues. 
For many years now, as a leader in the Florida Conference, my work has been marked by examples, integrity, and compassion. I believe as Tomlinson (1999) says: "Anything we want the teachers to do in the classroom, we should do with them as well." (Sterrett, 2011, p. 53). Consequently, I established a Summer Writing Clinic and a Summer Reading Clinic where teachers come to practice the art and science of teaching writing or reading along with school students. This has been a successful program because the teachers practice in the morning as I facilitate the learning, and in the afternoon, they continue their learning through reflection, study, and collaboration. I am an active leader "who accomplish[es] the real work of ... school" (Sterrett, 2011, p. 22). In addition to following the absolute ethics that God has established, I followed procedures as set forth by the Institution Review Board (IRB) and secured its approval for this study. I understand that I must "treat people as whole instead of subjects from which to wrench a good story" (Merriam \& Tisdell, 2016, p. 245). In order for the study to be trustworthy, I resolved to conduct it in an ethical and dignified manner.

\section{Protecting Against Personal Biases}

As stated in the section Researcher as Instrument, I am very connected to this study. I am very interested in the perceptions of teachers on any subject but particularly during change initiation, implementation, and the resulting institutionalization (Fullan, 1993). By practicing reflexivity, using triangulation, observing ethical practices, and by valuing people much more than the product of a study, I endeavored to maintain objectivity and transparency during the interviews, and through the reporting of the data, result of findings, and recommendations. 


\section{Protecting Human Subjects}

White, in her book Education (2003), states, "Fidelity to God involves fidelity to man" (p. 51). The duty of the researcher is to protect the participants in the study from harm of all kinds - physical, mental, and emotional. The participants in the study were protected through my transparency in open and clear communication. The participants had the right to sign a consent (see Appendix D) to participate after they had been informed of the following:

1. Purpose of collection the data. I related the purpose of the study to the participants as stated: Three primary purposes guide this qualitative case study. First, I wanted to examine the perceptions of teachers in regard to the adequacy of Professional Development to support the CCSS adoption by the Florida Conference. Second, I wanted to know how teachers are implementing the CCSS in their planning, teaching, and assessing. Finally, I wanted to understand teachers' perceptions of the impact the CCSS are having on student learning.

2. Confidentiality. The names of the participants were known only to me. Their names were coded for references and analysis throughout the data collection, analysis and reporting. Once the study was over, the names were filed and saved in my home to be destroyed after three years. One person on my dissertation team was my associate superintendent, Dr. Doran. She and I work well together and she agreed to help and support me through my dissertation even before I chose a topic. She, as well as the other dissertation committee members, did not have access to names of the participants. Dr. Doran's interest is to see me complete my study because it is my wish to do so.

3. Risks and benefits to participants. There are no risks to participants as this 
study is voluntary and participants may stop at any time during the process without any repercussions. Possible benefits of participation will be the fact that the participants have the chance to have their views, thoughts, feelings, and perspectives heard and reported. As a result, changes or understanding might be realized because they allowed their words to be heard. There will be no tangible or monetary benefits for this study.

4. Researcher's confidante. My research study chairperson, Dr. Burton served as my confidante, advisor, and counselor through this study. 


\section{CHAPTER 4}

\section{CASE STUDY FINDINGS}

\section{Introduction}

This qualitative case study focused on educators who teach in the Florida Conference of Seventh-day Adventists and their perceptions regarding the adequacy of the Professional Development to support the implementation of the CCSS.

The following questions were used to guide the study:

1. What are the teachers' perceptions regarding the adequacy of their Professional Development to support the implementation of the CCSS?

2. How are teachers implementing the CCSS in the classroom in terms of planning, teaching, and assessing?

3. What are teachers' perceptions regarding the impact of the CCSS on student learning?

\section{Interview Procedures}

For the interviews, we used ZOOM to allow for recording and it helped to keep the teachers' identity confidential since we did not have to meet in person. The participants and I agreed through email on a particular time and I sent an invitation with directions for them to sign on the ZOOM platform so we could hold our interviews. In 
most cases, the process went smoothly except for one participant who forgot to sign on because of prior traveling arrangement and another participant who signed on about an hour later than the appointed time. Before the interviews started, I greeted the participant, described the research, discussed confidentiality and reviewed the promise of anonymity. Then I clarified any questions though only two had a question. During the interviews, the participants were given the choice to appear on camera or not but I showed myself on camera. On different occasions, the participants were not very fluent in the technology so it was a relief for us both to simply be able to listen to each other. The participants sounded at ease and were patient and friendly.

\section{The Coding Process}

According to Saldaña (2014), "coding is analysis" (p. 9). But more than that, it is a way to attain a measure of logic and clarity about our world from our data and our deep reflections of them. Accordingly, after each interview, I listened to the Zoom recording and transcribed it word for word and typed it into a Word document. Then I read the transcript as I listened to the recordings to double check that each word was transcribed. Then I printed the document to read and re-read. "Coding well requires that you read, reread, and reread yet again" (p. 41).

I left the document unmarked and reflected about it in my mind for a day or so. I asked reflectively: "What did the participant say_truly say? "What do those words tell me as educator? As a researcher? Then I went back and read the document and used the exploratory method of Holistic Coding where I applied codes to large pieces of data in order to get the sense and spirit of the overall messages from the teachers (Saldaña, 2014). Each of the six interviews went through the same process of Holistic Coding. 
After all the six interviews had been holistically coded, I combined the responses to Research Question 1 from all participants to allow a broad look at this specific group of data. I did the same thing for the other research questions. I also combined the additional thoughts that the participants offered regarding the study. I read the interviews along with their codes and began the process of more detailed and focused coding.

"Coding is a cyclical act" (Saldaña, 2016, p. 9). It is a process of reading and coding and reading and coding until the data speak and answer to both the researcher and the reader. For the next part of the coding cycle, I chose the Eclectic Coding method which is the combination of two or more coding methods. I used a combination of Descriptive and Process coding in order to characterize the data and to relate the thinking and acting or the participants in the study.

\section{Study Findings}

Adequacy of Professional Development for Implementation

Research Question 1 asked, what are teachers' perceptions regarding the adequacy of their Professional Development to support the implementation of the CCSS?

\section{Perceptions of Adequate Preparation}

\section{Adequate Preparation}

One group shared they felt prepared to implement the CCSS because of training that they had received from other places-whether the public schools or through their educational training. Their perception of being prepared was not due to training that the Florida Conference had provided.

Ifelt prepared because I'd come from that background [from public 
schools where CCSS had been used].

I was prepared not because I was formally prepared by the Florida Conference but because I had done it in my own academic training. I think I finished my [advanced degree] program in 2012. There was a lot of talk regarding the Common Core in the courses I took for literacy.

Good question. I did. I do feel like I was prepared to be a teacher and whatever they gave me I would do.

I felt prepared because it wasn't that big of a change for me from the way I'd already looked at teaching math. (Participant has a degree in Mathematics and attends national conventions such as NCTM)

I was familiar with it from the public schools.

I had done a lot of research and reading and so when I was faced to having to teach it, I was prepared not because I was formally prepared by the Florida Conference but because I had done it in my own academic training. I think I finished my program in 2012 [an advanced degree]. There was a lot of talk regarding the Common Core in the courses I took for literacy.

I went to the Big Ideas training prior to coming to the Florida Conference.

\section{Inadequate Preparation}

Some participants perceived a lack of preparation to implement the CCSS. They believed that they did not feel prepared and the adoption of the standards has been a source of concerns for them.

\section{Inadequate Background in Mathematics}

Participants shared concerns regarding the lack of preparation to teach

Mathematics effectively. They believed adequate training in Mathematics would have prepared them to meet the teaching and learning demands of the standards and the academic needs of their students.

No. because they had changed so much in the way that we taught students, not necessarily I guess the content of the younger grades, but the 
methodology behind it has changed. I had never done it [taught like that] before. I'd never had those books. I still feel that way about the upper grades.

I think teachers are not equipped in general for teaching Common Core. It's designed to be, I believe, it's designed for math specialist to use. That's why for me it's easy to use so I'm in a different category and I just feel like a lot of teachers in the conference are suffering because they don't know the math well and that makes it more difficult to teach to the Common Core.

My biggest concern is that I didn't feel like they prepared us enough for math and when they rolled out the new curriculum. They told us to implement but they didn't teach us the new method. So, I'm a teacher teaching since 1989 and been teaching it one way and knowing how to do it one way and all of a sudden when I get the new book, I'm looking at it and I go: "What are they talking about?" . . I don't know if those books we are using if there's other Common Core books that are better. I don't know what the situation is but I wish we had more training in math

So I wish they had given [more training] even if there had been a one week course in showing us some of the methods that we needed in teaching the kids. So the younger method... the younger students is not a big deal. My biggest issue is with the older students. Even today, I spent forty [extra] minutes a day with my 8th graders. I don't have 40 minutes to spend with my 8th graders. I'm trying to explain to them this math stuff. . and how to do it in the way they want them to know. If I had been trained on how to do it, maybe I can get across the students easier.

The standards I guess are fairly simple to read and understand I mean they just say this is what you need to teach. My problem is how to teach it. And how to get the students to really understand it. I mean yes the conference has told us you need to have math rotations and all this other stuff and they've told us how to do that but when it comes down to it, especially the older grades, I don't feel like I've had the training to teach some of the math our $8^{\text {th }}$ graders need to know. It's not necessarily the standards cause the standards say you need to teach this that's great but the books say to do it this way but as a teacher who is not mathematicians, I struggle with that. They haven't given me a math class to teach me how to do it.

I think there should have been more training in the areas of math.

So, if anything, I think teachers need to be trained on how to use these concepts in more effective way and I think parents need to be informed. 


\section{Inadequate Initial Training}

Participants believed that it has taken them some time to come to a better

understand of the CCSS. They believe that initial training was lacking in preparing them to teach according to the CCSS.

Not at the beginning. No. It's probably taking me two or three years to really become comfortable in my own skin with them. To be honest, probably this year's been the most comfortable I've felt.

I guess I really wish that I'd have a little more in-service and training. I know part of that is I need to take the initiative and go get it, but I think it would have made my journey a little bit faster.

I think it would be good to have Professional Development about them [the standards].

My biggest thing about the common core is that they needed to train the teachers in common core maybe not the standards like I said, they said these are the new standards.

The conference gave us one or two short like one day in services on it other than that not really much at all. They just kind of said: "here's this new math then ... teach it. That's what it is."

So I wish they had given [more training] even if there had been a one week course in showing us some of the methods that we needed in teaching the kids

\section{No Formal Training}

According to the participants, they remembered short training from the conference when they presented the new Mathematics curriculum, Go Math! They don't recall having had formal training to unpack the CCSS and to understand their requirements.

I don't think I received any formal preparation, just my own reading and research. I don't know that we went to any formal training as we switched to an emphasis to the Common Core Standards.

I don't remember doing anything formal. Outside of my education, 
classes, I just remember being told about the Common Core and there was

a debate about whether or not it was beneficial to our school system.

The conference gave us one or two short-like one-day in-service-on it [CCSS]. Other than that, not really much at all. They just said: "Here's this new math," then, "Teach it."

When they were first introduced to me? I was familiar with it from the public schools, but as far as the Florida Conference, no.

\section{Planning, Teaching, and Assessing in the Age of CCSS}

The participants were asked, "How are teachers implementing the CCSS in the classroom in terms of planning, teaching, and assessment?"

\section{Using the Standards in Planning}

Participants shared the various ways they use the CCSS in their lesson planning.

Responses varied from those participants who used the standards to plan for long term, to

those who use them for daily planning, or to those who used a mixture of standards.

I don't check the Common Core as it were. I just trust that the standards that are online for the Adventist Edge and just assume that they're Common Core and that's what I'm using for my lesson planning.

I'm one of those people-probably not the best thing but I look at the standards when I make my yearly plan-my long-term planning but I don't look at them for my daily lessons. I don't plan daily lessons based on the standards. They're in the back of my mind but I don't say: "Let see, what the standards say?" and plan for my daily lessons. No, I don't do that. I know some people who do. I guess it's a matter of style. But I don't do that.

Yes, it does have an influence in my lesson planning. Now my lesson planning, instead of being: "Today we're doing page 98, 99," my lesson planning is built more around the standards and the big picture goals what I really want my students to accomplish. To be honest, I think I was heading that way personally anyway but I think the Common Core has really helped me to move that way.

As far as the standards go, I use the Common Core and the NAD of 
course. And I combine them together to see if I'm actually teaching the right thing to the students at the right time. So, the Common Core helps me to stay on track so that I can make sure that my students are up to par with what they need to learn as compared with other students in our state so they can be on track academically.

I follow the Common Core standards. I use the Big Ideas [Math Curriculum] which are correlated to the Common Core. I refer back to those in my lesson plan to guide me.

\section{Using the Standards in Teaching}

The participants indicated they had changed or shifted their way of teaching due to the CCSS. The changes in ELA have included different strategies that promote critical thinking in reading and deep reading in the content areas such as Social Studies. There's a greater focus on argumentative writing and writing across content. In Mathematics, the focus is more on providing tools for the students to use in solving problems.

Back in the 70's when I grew up, that was not the way I was taught. In college, I was not taught that way. We were taught to teach comprehension and other reading skills but not so much the higher order thinking. I had to change the way I do things. I've had to do training, webinar and I've had to take some classes so I can incorporate this stuff better: things like "How does that make you feel?" "What is your point of view?" "Write a different ending."

In math, instead of just teaching the kids how to do addition, subtraction, multiplication, and division, things like that, now we're spending a lot of additional time on learning different methods on how to do them using the distributive property, the associative property and even the commutative property where the kids now are learning tools that they can use to solve problems that they might not have been able to solve before so I'm spending a lot of time on the tools and that's had a pretty positive impact on my kids anyway.

The standards lead my curriculum. I have the textbooks and I have the curriculum but it is the standards that drive my lesson so I try to teach what the standards are and I try to find activities and materials that will make sure that the children have a good grasp of what the standards are.

Probably my focus on reading has increased. I'm trying to get my kids more interested in reading and to do all the other things related to that. 
A lot of it has to do with argumentative writing and so that forces me to make sure I teach kids how to be able to justify an argument and how to open an argumentative essay and how use examples and so on and bring the argument to an end. I guess if there wasn't an emphasis on the Common Core maybe I'd just read the magazine and do a few activities but because I know these are national standards I push my students.

So, yes, definitely and in social studies I didn't realize a lot of social studies is actually reading in there. deep reading the same thing so in social studies also, it's not just reading for materials but being able to navigate the textbook and pick on an argument and being able to now stop and reflect on what you've heard. Connect it to something you've read somewhere else and then write about it. So, definitely it has changed the way I teach.

Like we're doing math for example, we'd integrate writing with it. I call it "teaching your parents how to do the math" where they write all the steps how to do a certain kind of problems and they share it with their parents. In science for example, we do a lot more writing and that's integrated along with our writing class. And the writing is to help them learn how to present their research in a proper way. That's also integrated with the technology so they can produce the writing some sort of presentation whether it's a PowerPoint presentation or video and to demonstrate that they have mastered a standard or a set of standards. So, yea, I would say that the Common Core has increased my use of writing across the subject areas.

\section{Using the Standards in Assessing}

Participants shared that they used the CCSS to promote mastery in their students

instead of topic coverage. Their assessments are more purposeful and varied.

Assessments no longer consist of only pen and paper; instead participants have included

observation, content mastery, discovery, and performance.

Yes. Yes, absolutely. Now, my assessments are not so much "OK, we finish Chapter 1. So, we do an end of chapter review and at the end of the chapter test." My assessments are based on we learn how to accomplish all the tasks in a standard and then we assess that they have mastered that and we use that to build on to go into another standard so my assessments have really changed from paper and pencil test to performance test and just observation for example, when we learn how to do all the tasks and standards, I may ask a student to come up and demonstrate how to do a problem involved in the standards on my white board and I can immediately tell if they mastered it or not. 
Yes. You want to make sure that whatever standards that you're covering that they understand it.

I use the Common Core as the guideline to create assessment also for discovery. My goal for my students is that they discover them [answers] and not memorize them. I think that's how I see the Common Core in my classroom.

I may add a project if I think that some of the standards are not being assessed in the test I may add a project just to add to that.

\section{Perceptions of CCSS Impact on Student Learning}

The participants were asked: What are teachers' perceptions regarding the impact of the CCSS on student learning?

The participants shared their perceptions on the impact that the CCSS have had on their students, their parents, and themselves. Students who have been taught with the CCSS since the beginning of their learning journey or students who have been exposed to the CCSS for many years seem to show better understanding in grasping the various methods of instructional deliveries than those who were introduced to the principles of the CCSS at a later age such as at the middle school level.

\section{Positive Impact of the CCSS}

The students who come in in the younger grades, I see that they're actually doing better.

But my 3rd and 4th graders who've had it since first grade, they catch on really fast.

Those kids who are coming up through and I've had the Common Core for several years, I think they're learning how to think, how to problem solve, looking for patterns. I do see a difference that way.

I think having multiple ways to solve a problem rather than just one algorithm. I think the Common Core stresses that there's more than one way to do it and in that it makes it a safer environment for kids to try and explore and guess at the answers. Trying to formulate an answer without 
it being so frightening to them to get it wrong. They were afraid they might get the wrong answer in the past. I think they're more able to explore.

I've seen the most progress in math so far and I think that's part of my own personal journey. I think as years go by, I may note progress in the other subject areas as well.

What I have observed is with my students I'm seeing students now being able to use a little higher order thinking when they come to problems and so a lot of my students have an increased confidence when it comes to tackling whether it's math problems whether it's writing prompts because we've been working on tools and I like that.

Yes. I tell you about one today. I have a student who has started in our school 2 years ago, this is his $2^{\text {nd }}$ year not two full years. He started in the $3^{\text {rd }}$ grade and was probably functioning close to the second grade level with math and reading he doesn't come from an English speaking family so we did a lot of work with him his first year on not just memorizing the time table but actually to make sense of them with patterns, repeating patterns, relating 3's to 6's, and 9s to $12 s$ we do different hands on activities and to help him break apart what $4 \times 12$ really means so he got to the point where he's' not just memorizing and you can ask him: "what's $4 \times 12$ ?" and he can say: " $4 \times 10=40$ and $4 \times 2=8$ it's 48 "

And now he's gotten to where he can do that with problems like you might ask him what $6 \times 28$ and so he can break those apart and use different tools to really do them quickly and accurately by using mental math and today we were reviewing some strategies and principles and so we had a problem that was $8 x 898$ and he said: "Oh, I know how to do that!" and he came to the interactive white board and he did $8 x$ (900-2)

$8 \times 900$ and $8 \times 2$ and he subtract them and using the distribute property, he came up with the solution. It was amazing to watch him using different tools and principles that he's learned. For me, that was amazing. To come from a kid who couldn't do any multiplication to doing a problem $898 \times 8$ basically using mental math so I have several students that are like that I have another student who was struggling with division the common core teaches a method of doing division using easy multiplication facts he has pretty much mastered that now he can do long division with one digit or two digits by using some of the common core principles. That's really fun to see that. 


\section{Negative Impact of the CCSS}

\section{Negative Impact on Students}

The students who were in the old system who are now my older students, they have more trouble with it simply because they didn't learn how to do it that way from the beginning and now we're trying to teach them a new way of doing it and they're confused.

I think [students] they're not as well versed in basic facts. Things that kids used to have to memorize sometimes those things aren't down pat and they do affect their math grades.

Especially in the upper grade math. It is very difficult and it's very confusing to students who are used to seeing it one way and to parents who are used to seeing it one way.

\section{Negative Impact on Parents}

And parents are also confused with it and so it's almost like I have told my parents: "I'm not going to send math homework home because I don't want you to help with it because you are confusing them you're showing them one way and we're showing them a different way.

In the last few years, I've had a lot of frustrated parents saying: "My kid brings this home and he can do most of it, but he gets stuck on a problem and I don't know how to help him because it's done differently than I was trained to do as a child." And I get that and so, sometimes I actually bring parents in to show them what we're doing individually. I really need to start making a series of videos like a close time line so parents can see it. But I think that, if there is a negative aspect I think that would be one of them.

If I have one negative thing to say about the CCSS, it has to do with parents. One thing that I've noticed it has cut off the parents' ability to help their students sometimes in math. For example, if we drill, drill, and drill on how to use distributive property to do multiplication or division or a certain kind of thinking map when we 're doing writing or science or social studies other than math, these area not techniques or methods that parents have used.

The other, if there's a negative aspect, and I think it's based on just parents learning to do things in a different way, is that a lot of the parents have started with a mistrust of the Common Core principles. 
We can do our best in the class but if it's not being implemented at home and if the parents don't really understand what Common Core is and how their children are affected by it, then it makes it even more difficult for the teacher. So if anything, I think teachers need to be trained on how to use these concepts in more effective way and I think parents need to be informed.

\section{Classroom Observations}

Visitations in two classrooms contributed to the data for this study. I visited two schools which were in close proximity to my residence and work and did not require long traveling.

The first classroom I visited was a Mathematics teacher and the second was a teacher who taught literacy. Both teachers taught Middle School age students. Notes from our interview helped to supply the background for my field notes. Information obtained from the CCSS website along with the literature about them, also allowed for confirmation of those practices observed in the classrooms.

\section{Observation of Instruction: ELA in a Florida Conference Middle School}

When extracting data from the observation and the lesson plans obtained from the ELA teacher, the current shift in perspective for the teaching of ELA provided the lens through which I analyzed the various points that I gathered from the field notes. One morning visit is not able to describe the life work of a teacher and therefore, this analysis will not aim toward that goal. Rather, it will focus on the few observed points seen only through the lens of the current shifts in education as appropriated by the CCSS.

Observation of instruction delivery, video, and lesson plan showed a focus on the usage of complex text. The class read an article entitled "Equal Pay for Equal Play" where words were highlighted to draw the students' attention. Words such as: 
discrimination, notion, revenue, and discrepancy. Other words that were not highlighted but can be considered important in the academic discourse were: compensated, accelerated, disparity, allege, wage discrimination, male dominated, generate, and leverage. This is a required element of the CCSS that all students should have regular practice with complex text and their academic language (Alberti, 2012; NGA \& CCSSO, 2010; Shannahan, 2012). However, the vocabulary focus that the CCSS require was absent during the lesson.

The class read the article from Scholastic and viewed a video from the same source. This was done for reading and writing. After the reading, the students were to write an argument piece to take a stand for or against equal pay between men and women athletes, to take a side, and to show evidence. Both reading and writing were focused on finding textual evidence for argument. The argumentative essay called for evidence to support claims, reasons validated by evidence from sources, and clear information. The teacher admonished "Don’t just write your opinion. You need evidence from the article. Don't let emotions run with you!" This lesson is an example of reading, writing, and speaking grounded in evidence from texts, which is an educational shift mandated by the CCSS (Alberti, 2012; NGA \& CCSSO, 2010; Shannahan, 2013; Shannahan \& Shannahan, 2017).

\section{Observation of Instruction: Mathematics in a Florida Conference Middle School}

One morning, I visited a middle school Mathematics classroom. I arrived a few minutes early before the students entered the room. That allowed for some time for the teacher to orient me to the classroom, the lesson plans, and the objectives for the day's 
lesson. The teacher welcomed me and showed great care that I was comfortable and ready for the instructional activities ahead. The teacher and I discussed my research topic once more and she reiterated what she had shared from the interview that she believed the teachers from the conference were not prepared to teach Mathematics because "it required deep understanding of the subject." She further added, "It would have taken the conference a lot of time to train them to."

From the lesson planning, observation of instructional delivery, and the teacher interactions with the subject and the students, the topic under study met the grade level CCSS expectations. The CCSS has designated content to progress across the school years in order for there to be a greater focus on fewer topics for each grade level. The class studied the concept assigned for that grade based on the CCSS 7.RP.A.3: Use proportional relationship to solve multistep ratio and percent problems. Examples: simple interest, tax, markups and markdowns, gratuities and commissions, fees, percent increase and decrease, percent error. Further, the CCSS call for there to be coherence and rigor in the delivery of Mathematics instruction and assessment.

There was logical and systematic flow in the lesson delivery, strategies used, and activities planned for the lesson which accounts for a coherent and well thought out lesson delivery. The teacher established the following purpose or goals for the lesson: the students will

1. Know how to derive the Percent Equation from the Percent Proportion.

2. Know how to find a part of a number, a percent, or a whole using the Percent Equation.

3. Apply the Percent Equation to solve multi-step, real life problems involving 
tips, taxes, tithe, and sports.

Based on the goals of the lesson, the students went through a progression of activities:

1. Warm Up: Practice changing decimal into percent then into fraction. After providing clear directions and examples, the teacher released the students to walk around and to find a partner to practice their conversion skills. This activity, aptly named QuizQuiz-Trade, allowed for each student using a problem on an index card, to pair with another student and each ask the question on the card, discuss, and move on to another (Quiz). The pair split to another pair and they do the same thing with another partner (Quiz). This new pair separated and met another pair where they switched quiz card with that person (Trade). The activity continued until the time for practice had expired and the students regrouped to move on to the next activity.

2. Motivation and Background. The next activity served as a motivator, an introduction to the day's lesson, and a way to provide background knowledge to support the learning. In this activity, the students held a basketball tournament. They formed a line and each student took turn to shoot a ball into the basket. They shot a total of 50 baskets in all and recorded the data of successful and missed shots. The data from the tournament provided the materials for the lesson that followed it.

3. Guided Lesson and Independent Practice: Finding a part of a number, a percent, or a whole using the Percent Equation. During the lesson, the class used the data from the basketball tournament to answer the following questions/problems:

1. What percent of the shots did the class make?

2. What percent of the shots did the class miss? 
3. Use the percent proportion to figure out percent.

During the lesson, the students and teacher's discussions led them to make many connections to real life events such as: tithes (1/10) offerings (5-10\%) tips (12-20\%) and taxes. The teacher paused and posed a question for the students to ponder and share: "Do you know what Florida's sales tax is?" They discussed among each other, and responded.

They continued to communicate within the context of the activity and to utilize the commutative property, which is a reference to early learning that was still meaningful and relevant in the 7th grade learning of percent proportion and percent equation.

The lesson delivery and learning was rigorous and precise. This is an affirmative response to the call for rigor from the CCSS. This class responded well by moving through procedural skills and fluency in an effort to develop speed and accuracy in the calculation of mathematical problems. All of the learning moves in this class show great precision in learning as students persevered and gathered the data needed to work out questions accurately.

After the lesson, the students work in collaboration to solve multi-steps, real life problems independently. They are instructed to:

1. Work together in a group to solve the problems.

2. Explain and defend to another group.

3. Explain and describe the process that brought them to their answers.

\section{Classroom Observation and the Eight Principles of Teaching Mathematics}

In addition to the three major shifts of focusing on fewer topics, teaching with coherence, and learning with rigor, the CCSS have mandated that eight principles of 
mathematical practice be taught. They are as follows:

1. Make sense of problems and persevere in solving them.

2. Reason abstractly and quantitatively.

3. Construct viable arguments and critique the reasoning of others.

4. Model with Mathematics.

5. Use appropriate tools strategically.

6. Attend to precision.

7. Look for and make use of structure.

8. Look for and express regularity in repeated reasoning.

During the visit to the Mathematics class, I reflected on the fact that all the principles of Mathematics teaching were present in one learning experience or another.

\section{Principles A}

1. Make sense of problems and persevere in solving them.

3. Construct viable arguments and critique the reasoning of others.

6. Attend to precision: students worked together to solve problems and to report/defend to others.

Those three principles were at work when students answered the various questions such as:

1. What is this in percent?

2. What is this in fraction?

3. What is this in decimal? 


\section{Principles B}

2. Reason abstractly and quantitatively.

5. Use appropriate tools strategically.

6. Attend to precision.

The students used various tools to solve their problems. They used mathematical language and communication to reason out their solutions. At one point, the teacher shared: "Remember I said it's my favorite way to find equations? You can give me your opinion" (italics supplied).

\section{Principles C}

4. Model with Mathematics.

7. Look for and make use of structure.

8. Look for and express regularity in repeated reasoning.

The students used real world models to discuss and solve percent proportion and equation. The use of a basketball tournament and the related discussion about the super bowl created meaningful mental models for the students. The teacher led the class to use the structure for a percent proportion $(a / w=p / 100)$ then moved them to write it as a percent equation $(a=p \cdot w)$ or $(a=w \cdot p)$ as the order does not make a difference (commutative property).

\section{Overarching Themes}

Saldaña (2016) describes a theme as something that may be "an outcome of coding, categorization, or analytic reflection" (p. 15). "A theme brings meaning and identity to a recurrent [patterned] experience ... and captures and unifies the nature or 
basis of the experience into a meaningful whole" (p. 199).

Early in the interviews and throughout the coding process, certain patterns or overarching themes appeared in the data. In order to share condensed ideas and meaning to the lived experiences and the perceptions of the participants, three distinct themes have been identified. The first theme is the idea of an array of learning. The second is a call for specificity in learning; and the last is marked by a drive for effectiveness in learning and teaching.

\section{An Array of Learning}

Heidi Hayes Jacobs (2010) in her book Curriculum 21: Essential Education for a Changing World declares that "those communities that have been able to create and sustain engaging innovation want growth, not nostalgia. There are real dangers in glorifying the good old days and clinging to our schools' myths and stories. How can we grow the curriculum if schools are shackled by memories?" (p. 15). To add to Jacobs' thoughts, is the idea that as a Christian institution, the words of Deut 28:13 promise that:

The LORD will make you the head, not the tail. If you pay attention to the commands of the LORD your God that I give you this day and carefully follow them, you will always be at the top, never at the bottom.

These two ideas suggest that it is an excellent goal to pursue change and growth.

Throughout this study, the theme of recurrent learning surfaced. Many of the participants shared about their participations in different trainings and their work with various curricula and several initiatives such as: Pathways reading program, Writing portfolio, Science by Design, 4MAT teaching strategy, or Step-Up (Student Success) program. The participants in the study were familiar with professional development activities. 
OK well in reading when they rolled off the Pathways, they started even before the Union had adopted the Pathways they started giving us training. It was more than just the one-day in-service. They had training upon training upon training. They had teachers who were piloting the program they would pull us together tell us what they have found, the best practices they had done. The writing program, the writing folders and portfolio we were using we were trained in that. There were even videos made that we can go back and watch and there were two- or three-day training where they would pull us in Orlando and give us those training.

\section{A Call for Specificity in Learning}

Proverbs 22:6 admonishes to "train up a child in the way he should go, and when he is old he will not depart from it." This is in no way to compare educators to children in the sense of the word. However, we move from childhood to maturity in our continuum of learning. Every time something is new, we are back to the proverbial Kindergarten making our way to understanding and meaning. Teachers needed to be trained on the specifics on the CCSS.

While the data indicate that the participants have been participated in various types of training, it also shows that more Professional Development training was needed about the CCSS for the teachers. The data show that they received none to little training from the Florida Conference. The training that the teachers received was more a mention during the training for the Go Math! curriculum adoption. Perhaps, the most surprising finding was the fact that there appears to be confusion among the participants about the trainings they have received and how they were related and not related to each other. One example is the fact that the CCSS were adopted in the Florida Conference in the year 2012; yet in the interviews many of the participants mentioned the Pathways reading program which was in effect long before the CCSS. Pathways was adopted in the year 2008, a full four years prior to the adoption of the CCSS when the shifts in ELA had not 
been in place along with the CCSS. Additionally, responses from the participants demonstrated a lack of specificity about the various standards that they used to inform their instructional and assessment practices. The participants referred to the Adventist Edge Standards, the NAD standards, the CCSS, the standards that go with the curriculum (Scholastic and Big Ideas were mentioned) and the pacing guide.

"As I said, I know that I've gone to the Step-Up for success stuff." The above statement is telling because the discussion for the study is focused on the CCSS yet the response from the participant is about the Step-Up program. The participant is referring to a parent engagement program that originated from the Step-Up, which is a scholarship program that allows students to choose private schools or public schools that are outside their school districts. In 2014, the organization began a two-year Professional Development that would support student success and ensure parental engagement. The fact that the parental engagement program began close to the adoption of the CCSS does not mean that they are related.

\section{A Drive for Effectiveness in Learning and Teaching}

A key, but somewhat unexpected finding, is the fact that the participants in the study did not begrudge the fact that the CCSS were adopted. They did not offer personal bias against the CCSS. Instead, they discussed the impact that the CCSS had on their students, the parents and themselves. They shared both positive and negative impact of the CCSS and their sorrow over not having been trained adequately and their desire to learn more and to meet their students' needs.

I just really never minded doing them [the standards] because I do believe it's probably the correct way to teach kids to give them a deeper understanding so they're not just grasping at algorithms but although it's 
always been the way I taught. I think teachers are not equipped in general for teaching Common Core.

Many comments were made about the participants trying to learn and to make sense out of the CCSS. They had concerns about the impact of the CCSS on their students' progress and the responses of the parents. However, as educators, over and over, they shared how much they would have liked to be trained and be prepared to use the CCSS. The fact that the teachers learned about the CCSS from places that are apart from the conference, indicates a desire for learning and a willingness to grow. The following comment summarizes the sentiment:

Personally, I feel that it is commendable -the Florida Conference should be commended and the NAD for adopting the Common Core. I think that even though we are parochial and independent, it is very important that our students be able to compete nationally. We know we're training them for eternity and not just for the here and now but I think in order for them to make an impact in the political world and the social world it's important for them to make an impact. I think they need to be able to meet these CCSS in order to study at the best universities and be able to have an influence in the way things are done in this country. So, I personally don't just think that we should prepare our students just for to preach the gospel because even that that is changing now in ways of doing that so I think it's very important that we stick to the Common Core but that we make our teachers more aware of why it is important and we make sure that we're training them so they have access to the appropriate modern materials that we'll be able to meet the CCSS and objectives. 


\section{CHAPTER 5}

\section{SUMMARY, DISCUSSION, \& CONCLUSIONS}

\section{Introduction}

The CCSS arrived on the American educational system in June 2010 with specific shifts that would guide and determine the path that teachers take toward preparing their students for college and career (Conley, 2011; Farmer, 2014). The CCSS provide guidelines for a universal way of thinking about teaching and learning. While they do not mandate what and how teachers teach their students, they do provide a set of learning goals that every child should be able to do at every level from Kindergarten to Grade 12 (NGA \& CCSSO, 2010).

The Florida Conference adopted the CCSS in preparation for the school year 2012-2013. The CCSS adoption arrived with the new Mathematics curriculum, Go Math! for Grades K-5 and Big Ideas for Grades 6-8. During introduction and follow up training for the new Mathematics curriculum, the CCSS were mentioned-specifically the ten principles of the teaching of Mathematics.

In the context of the adoption of the CCSS by the Florida Conference of Seventhday Adventists, the purpose of this study was to

1. Examine the educators' perceptions regarding the adequacy of the Professional Development they received to support their implementation of the CCSS. 
2. Identify the ways they were implementing the CCSS in their planning, teaching, and assessing.

3. Understand their perceptions of the impact the CCSS were having on student learning.

\title{
Review of CCSS Related Literature
}

\author{
Educational Shifts in CCSS for \\ ELA and Mathematics
}

The CCSS brought certain shifts in the way educators teach ELA and the Mathematics (Alberti, 2012; NGA \& CCSSO, 2010; Shannahan, 2012, 2012-2013; Shannahan \& Shannahan, 2017). These shifts are not representatives of the manner teachers are used to teach and to think about the learning process. Rather, the CCSS require that teachers look at teaching in different ways than before (Sawchuck, 2012). The educational shifts call for teachers of ELA:

1. To provide regular practice with complex text and academic language

2. To ground reading, writing, and speaking in evidence from texts - literary and informational

3. To build academic knowledge through content-rich nonfiction.

The educational shifts call for teachers of Mathematics:

1. To focus on fewer topics at each grade level

2. To develop Mathematics coherence which provides for continuity of learning from one grade to the next level

3. To provide rigor in Mathematics in order for students to develop deep and true command of the concepts taught in each level (NGA \& CCSSO, 2010). 


\section{Concerns Regarding the CCSS}

With this new set of standards came many concerns from educators regarding the lack of familiarity and opportunity to participate in the CCSS selection process. Across many states, teachers lamented that they were not adequately prepared and informed about the CCSS (Exstrom \& Thatcher, 2014). They worried about the implementation of the CCSS, the types of assessments that would show evidence of the CCSS success, and the cost of the CCSS in terms of materials and resources (Farmer, 2014; Rothman, 2012a).

While educators criticized the adoption of the CCSS based on their perceived lack of sufficient knowledge of the CCSS to translate them into student success, parents also believed they were left in the dark. The administrators and teachers, who would otherwise guide the parents toward understanding and subsequent acceptance of the CCSS, were no more prepared to carry out the CCSS nor to educate the parents about the CCSS and their impact on the education of their children (Maunsell, 2014).

\section{Professional Development}

\section{Professional Development in Time of Change}

The most important factor in educational reform is the effectiveness of the teacher (Culham, 2014). It is imperative that teachers receive the type and amount of training necessary in order to make a decisive and productive shift in thinking and educating students. Teachers will teach as they were taught (Guskey, 2014), unless they are adequately prepared to carry out changes that are necessary and supported by current research and requirements such as the CCSS. 


\section{Fullan's Three Steps to Change}

Fullan (2007) shares three phases of change that would help educational leaders to carry out reformation in a way that honors the teacher and that promotes success in the implementation of the change and the resulting impact on student learning.

The first phase in the change process is the initiation stage. This is the beginning of the process where it is apparent that change is necessary and that the need for the process is warranted. In the case of the CCSS, the Florida Conference would have initiated the CCSS based on many factors such as: the presence of low standardized scores especially in Mathematics, the need to be up to date with current educational thinking, practices and initiatives, or an effort to meet parental, community, and professional expectations. Regardless of the reasons, there should have been an initiation phase of the change effort.

\section{Purposefulness and Professional Development}

During the initiation stage, Professional Development must be purposeful. It is very important that change leaders approach the change initiation with the singular purpose of teacher learning (Hall \& Hord, 2011). Teachers' initial exposure to a concept should not be passive. It should give the teacher the opportunity to engage in learning through various approaches such as role playing, classroom observations and live modeling in order for them to have clarity about the new practice (Gulamhussein, 2014). Teachers who are responsible to meet the demands of the change must be clear, informed, and educated in order to make it possible for the change to go forward into the next phases. "Professional learning is a critical component embedded in the change process" (Hall \& Hord, 2011, p. 6). 
The second phase is the implementation stage where change leaders and teachers work together to put the ideas for change into practice. It is very important that learning goals are identified, evidence of learning be established, and evaluative criteria be designated for follow up. During that phase, the change implementers must work together to establish purpose, receive instruction about the change, utilize opportunities for practice collaboratively, and finally, to put the change into the work of teaching.

\section{Productivity and Professional Development}

Professional Development must be productive. Time and resources must be allocated in order for the training to be profitable and useful to teachers. The time allotted must be significant and ongoing. Teachers must have enough time to learn new strategies and to wrestle with implementation issues (Gulamhussein, 2014).

In implementing change, it is important to remember that change is not an event. It is an important process (Hall \& Hord, 2011) through which the people and organizations gradually and systematically learn, understand, and become skilled and competent in the use of the new ways that the change has brought. Teachers must receive support during implementation. Teachers may transfer new skills into their teaching practice only $10 \%$ of the time when the learning was merely described to them. On the other hand, when teachers are coached through the uncertain phase of implementation, and when they have models of good teaching, $95 \%$ of them can transfer the skill into their teaching. Modeling is highly effective. Teachers will best understand the how's and why's of implementation when an expert model the new practice for them.

This process takes time-perhaps three to five years (Sterrett, 2011, p. 51). Additionally, expert and material resources must be provided through the entire process 
in order for the implementers to use the change with fidelity and flair.

Fullan's last phase is the institutionalization stage where either the new change becomes part of the culture or fabric of the organization, or it simply dies a quick death on a lonely dusty school shell. Change implementers need all the support necessary to maintain the change and to be sure that it is implemented with integrity. Coaching and mentoring (Joyce \& Showers, 2002) are great tools during this phase as teachers become more and more comfortable with the new change, they may seek suggestions, answers to questions, or someone who understands the process. Much more than anything, teachers need to continue to train, reflect, and sharpen the saw of the new learning.

\section{Personalization and Professional Development}

Professional Development must be personal. While the adoption of change is the work of organizations, the success of the change starts and ends with the individual (Hall \& Hord, 2011). It is vital to consider each individual during the change process especially at this phase where teachers learn at various speed. One size training does not meet the needs of all teachers (Tomlinson, 1999, 2014). Professional Development is best delivered in the context of what is personally beneficial to the teacher for example, the teacher's subject area or grade level. To offer training on topics that are generic is useless in the context of teacher development and student learning improvement.

Teachers may learn at different pace and acuity therefore; appropriate time and resources must be allotted to meet the needs of individual teacher. "Anything we want the teachers to do in the classroom, we should do with them as well." (Sterrett, 2011, p. 53). Furthermore, interventions must be targeted at the individual level to ensure that each teacher is successful and that the change is impacting student learning in a positive way. 
Only after teachers are well trained and supported through the initiation, implementation, and institutionalization of a change process, can they be evaluated purposefully, productively, and personally.

\section{Method}

Population

This study drew from the population of the educators who work in the Florida Conference of Seventh-day Adventists since the inception of the CCSS in 2012. Florida Conference, with its headquarters situated in Altamonte Springs, Florida, is part of the worldwide Adventist church.

One of the departments in the Florida Conference is the Department of Education. It directs about thirty elementary schools with about 205 teachers in the Grades $\mathrm{K}-8$; four high schools (academies) and 14 child care centers. The schools are divided into zones by north, south, central, and west Florida. Currently, the Florida Conference Department of Education is directed by a Vice President of Education and four associate superintendents and their support staff. These individuals share the work of overseeing schools, supervising educators, evaluating and recommending/mandating curriculum and educational processes, recruiting and supporting teachers and staff, and planning and delivering conference-wide training.

\section{Criteria for Participation}

The purposive sampling allowed for participants who would provide the best information for the study. It was important that participants have firsthand knowledge about the case under study. Consequently, participants were purposely chosen among two 
different types of teachers from the Florida Conference: ELA and Mathematics teachers and two levels of teaching: primary (Grades $\mathrm{K}-5$ ) and intermediate (Grades 6-8). All participants were educators who worked in the Florida Conference since the inception of the CCSS into the organization in 2012.

\section{Participant Selection}

During the fall of 2016, I constructed a list of the educators who worked in the conference since the adoption of the CCSS. The names, schools, and grades were submitted to me by the Florida Conference. I wrote each name on a small card with identifiers such as: name, school, grade (s) taught, primary or intermediate. The identifiers were on one side except for the name which was on the other side by itself. Then, I divided the names into two piles: Primary (Grades K-5) and Intermediate (Grades 6-8). Participants were randomly chosen from these groups. Some of the invited teachers were not able to participate, therefore, I continue to select names randomly I obtained the desired sample size. Demographics descriptors are found in Table 1.

Among the respondents, there were: four coded as intermediate and two as primary. I converted one intermediate (SPI-10) into a primary because that teacher met both criteria. Now I had three primary and three intermediate educators, I inspected for other characteristics and the results yielded the following. Three participants were female and three were male. Three were White, two were African American, and one was Hispanic. They taught various grade levels: $3-4,4-5$, primary (not reported), 5-8, 6-8, and 6-9. The teachers varied in the number of years they taught. The participants' schools were situated in various parts around the location of the conference and were of various sizes. 


\section{Data Sources}

The data for this study was of three types. First, six interviews were conducted with the sampled educators. Then, two classroom observations were conducted as a follow up to the interviews. Those two teachers were chosen because of their location, access to me, and the subject matters that they taught. Since their subject matters differed from each other, the observations allowed for better clarification of the interview findings related to ELA and Mathematics. Finally, documents such as a lesson plans and photographs of posters and anchor charts were analyzed from the classes observed.

\section{Data Analysis}

\section{Interview Coding Process}

Six participants were interviewed for this study. After each interview, I listened to the ZOOM recording and transcribed it word for word and typed it into a Word document. Then I read the transcript as I listened to the recordings to double check that each word was transcribed. Then I printed the document to read and re-read.

I left the document unmarked and reflected about it in my mind for a day or so. I asked reflectively: "What did the participant say_truly say? "What do those words tell me as educator? As a researcher? Then I went back and read the document and used the exploratory method of Holistic Coding where I applied codes to large pieces of data in order to get the sense and spirit of the overall messages from the teachers. Each of the six interviews went through the same process of Holistic Coding.

After all the six interviews had been holistically coded, I combined the responses to Research Question 1 from all participants to allow a broad look at this specific group of data. I did the same thing for the other research questions. I also combined the 
additional thoughts that the participants offered regarding the study. I read the interviews along with their codes and began the process of more detailed and focused coding. All data were collected for analysis with no further data collection.

I chose an Eclectic Coding method which is the combination of two or more coding methods. I used a combination of Descriptive and Process coding to describe the data and to show the acting and thinking of the participants.

\section{Classroom Observation Coding}

Two classroom observations were conducted for this study — an ELA and a Mathematics class. During the observation, I took copious field notes and gathered lesson plans and photographs. The CCSS shifts and the ten principles of teaching Mathematics served as the framework for the analysis of observation data. After each observation, I reviewed the field notes and the lesson plans and compared them to the CCSS shifts and the principles of Mathematics teaching. This helped me determined the fidelity with which teachers implemented the CCSS.

\section{Insuring High Quality Results}

\section{Triangulation}

Triangulation allowed for checks and balances in the data collection and analysis processes in this study (Patton, 2002). The six participants in this study provided different sources of data gathering. These sources came from varying racial background, gender, school size, and length of time in teaching. Using different participants served to strengthen the data in the study. Instead of interviewing just one person and allow that one voice to speak, several participants were chosen in order to obtain useful and credible 
information from a purposeful sampling of participants.

The participants' grade level also added balance to the data. Three teachers taught at the elementary level and three taught at the middle school levels. These brought insight from the respective view and needs of their particular grades.

Different types of data allowed for triangulation as well. For this study, the use of field notes observations, lesson plans, photographs, and interviews allow for a broad range of data and for the ability for each to cross check the other. Observations allow the researcher to cross check what was said in the interviews and to gain better understanding of the data. The lesson plans gave me a glimpse of the work behind the lesson delivery and their analysis added richness and depth to the study (Patton, 2002).

\section{Reader's Feedback}

One way to assess the credibility of a study findings is through feedback from readers. The readers ask question, examine the evidence of the study, and balance the writer's interpretation and perspective with their knowledge of the field or the case (Miles, Huberman, \& Saldaña, 2014).

Two types of readers contributed in the assessment of this study report. A colleague in my academic field who works in the Florida Conference and who is a part of my dissertation committee has reviewed the document for form, grammar, and content clarity before the members of my dissertation committee review it once more. The members of my dissertation committee_-practitioners and researchers in the field of education - have provided guidance for the work. At each editing phase, the document was submitted to several readings and feedback was provided by both sets of readers. 


\section{Ethical Considerations}

A research study proposal was submitted to the Andrews University Institutional Review Board for approval in order to ensure ethical practices in research. Initial contacts of the participants and interviews scheduled were made only after the approval of the research study by the Institutional Review Board.

All participants were assigned a code name based on their grade level and the order they were randomly picked. Each code name began with SP (Study Participants), followed by the teaching level whether primary or intermediate (P) or (I), and finally with the order of selection. Example, 4th picked would be indicated by the number 4 . A participant who is a primary teacher and who was chosen 4th would be coded as SPP-4. All identifiers have been removed from the participants' description table about participants who might be easily identified.

\section{Findings and Discussion}

\section{An Array of Learning}

Throughout this study, the theme of recurrent learning surfaced. Many of the participants shared about their participations in different trainings and their work with various curriculum initiatives. Participants were familiar with training in various forms such as one-day training or Professional Development in the context of a study group. Participants mentioned several Florida Conference initiatives such as the Pathways reading program, Science by Design, the 4MAT teaching strategies, the writing portfolio process, or the Step-Up (Student Success) program during the interviewing process. They expressed knowledge and agreement that Professional Development training is a very important support for the effectiveness of teachers. 
$O K$, well, in reading when they rolled off the Pathways, they started even before the Union had adopted the Pathways they started giving us training. It was more than just the one-day in-service. They had training upon training upon training. They had teachers who were piloting the program they would pull us together tell us what they have found, the best practices they had done. The writing program, the writing folders and portfolio we were using we were trained in that. There were even videos made that we can go back and watch and there were two- or three-day trainings where they would pull us in Orlando and give us those training.

There was some in-service on using the Go Math! program and there was some in service on using the By Design science program.

"Professional learning is the key to improving instruction" (Scherer, 2014, p. 7).

The fact that the Florida Conference teachers have been able to participate in various different Professional Development opportunities agrees with the literature that professional learning is an important process in teaching improvement and student learning achievement. Professional learning is a very important part in the process of change (Hall \& Hord, 2011). Without effort, the participants named several trainings that they received from the Florida Conference, that is a testament to the time and effort that the conference takes to support and educate its teachers.

The participants described a variety of learning opportunities that were provided by the Florida Conference which included seminars, teacher coaching and mentoring, and the study group format which Goodwin (2014) advocates as being the best way to structure professional learning community in a school is to have small teams of educators learning and collaborating together.

\section{A Call for Specificity in Learning}

Perhaps the most surprising finding in the study is the fact that the participants who have worked in the Florida Conference, a leader in Professional Development activities and initiatives, did not have clarity between the various trainings, curriculum 
adoptions, and the CCSS. Most discussed the Pathways reading program, along with 4MAT, Science by Design, Conference Writing Initiative, and Step-Up in the same breath as they discussed the Mathematics curriculum adoption that came with the adoption of the CCSS: Go Math! and Big Ideas Mathematics programs. Moreover, when the participants spoke about training for the CCSS, they were referring to the limited training they received about the Mathematics curriculum. It is clear that the participants had had training in other areas but the training for the CCSS had been unclear. Therefore, while the conference has in the past taken care to train and nurture the implementation of other initiatives such as the Pathways reading program or the writing portfolio process, it was not so for the adoption of the CCSS.

The participants were also uncertain about the standards that they use to plan, teach, and assess their students. When asked how they were using the CCSS, they mentioned the CCSS along with the NAD, Adventist Edge, Pathways reading pacing guide and study guides.

$O K$, well, in reading when they rolled off the Pathways, they started even before the Union had adopted the Pathways; they started giving us training. It was more than just the one-day in-service. They had training upon training upon training. They had teachers who were piloting the program they would pull us together tell us what they have found, the best practices they had done. The writing program, the writing folders and portfolio we were using, we were trained in that. There were even videos made that we can go back and watch and there were two-or three-day training where they would pull us in Orlando and give us those training.

There was some in-service on using the Go Math! program and there was some in service on using the By Design science program but to be honest, most of it has just been me sitting down and with the standards and just wrestling and learning how to implement those on my own.

No. Has there been any offered? Do you know?

I don't think so. I don't remember. No. not on standards. As I said, I know that I've gone to the Step-Up for success stuff 
I follow the CCSS. I use the Big Ideas which are correlated to the Common Core. I refer back to those in my lesson plan to guide me. I use the Adventist edge website. The NAD website with all the curriculum and the standards and so on. I use that and I think it's the same thing as the Adventist Edge website. They sound very much the same. Because when I use other materials like scholastic news and so on. The objectives are similar to what I find on the Adventist Edge and the NAD websites.

As far as the standards go, I use the Common Core and the NAD of course. And I combine them together to see if I'm actually teaching the right thing to the students at the right time.

I don't check the Common Core as it were. I just trust that the standards that are online for the Adventist Edge and just assume that they're Common Core and that's what I'm using for my lesson planning.

The conference gave us one or two short-like one-day in-service-on it [CCSS]. Other than that, not really much at all. They just said: "Here's this new math." Then, "Teach it."

The kind of training that the participants received regarding to the CCSS goes contrary to what the literature promotes regarding professional learning. According to Dufour (2014), professional learning development must:

1. Follow a clear and concise path. It must be "ongoing, with sustained, rather than episodic and fragmented focus"

2. It must be collective rather than individualistic.

3. It must be job embedded with teachers learning as they engage in their daily work.

4. It must be result oriented with activities directly linked to higher levels of student learning.

A Drive for Effectiveness in Learning and Teaching

A key, but somewhat unexpected finding, is the fact that the participants in the study did not begrudge the fact that the CCSS were adopted. They did not offer personal 
bias against the CCSS. Instead, they discussed the impact that the CCSS had on their students, the parents, and themselves. They shared both positive and negative impact of the CCSS and their sorrow over not having been trained adequately and their desire to learn more and to meet their students' needs.

The participants shared that they would have liked to have training about the CCSS and the new shifts in teaching according to CCSS. The study shows that the participants would have welcomed Professional Development activities and are still eager to participate in learning. They related their own reading, research, and collaboration they have done about the CCSS in order to gain knowledge about the CCSS and its requirements.

So, if anything, I think teachers need to be trained on how to use these concepts in more effective ways and I think parents need to be informed. I guess I really wish that I'd have a little more in-service and training. I think it would be good to have Professional Development about them [the standards].

I don't think I received any formal preparation, just my own reading and research. ... I don't know that we went to any formal training as we switched to an emphasis to the Common Core Standards.

I guess I really wish that I'd have a little more in service and training I know part of that is I need to take the initiative and go get it but I think it would have made my journey a little bit faster.

In reading, Common Core has made more sense by the way they want us to implement Pathways, also being with the Step-Up program with the standards they have to help you do your lesson plan and stuff, that I think makes it easy with reading.

"In times of great change, it is not unusual to miss the obvious" (Jacobs, 2010, p. 80). A teacher's efficiency is tied directly to student success. A teacher who desires to learn and grow seeks a good thing. In every change, the teacher remains the most 
important component in the process (Hall \& Hord, 2011). In Insight into Action (Sterrett, 2011), Dr. Carol Ann Tomlinson notes that: "Anything we want the teachers to do in their classroom, we should do with them as well" (Sterrett, 2011, p. 53). There's no question that the CCSS were adopted in order to influence growth in teaching and learning. However, that must apply to both teachers and students. The first step toward student achievement is to be certain that teachers are well trained and prepared to support the learning needs of the students.

Fullan (2007)'s three steps to change provides a great model for Professional Development that promotes success in learning and teaching. In the case of the CCSS, the initiation phase would have introduced the new CCSS and their shifts in teaching along with the reasons, purposes, and goals for the change. It would have provided the learning necessary for the teachers to implement the CCSS in the classroom, instruction about the new shifts in teaching, and the appropriate and use of the materials necessary to meet the demands of the CCSS.

The implementation phase would continue to translate ideas into real classroom practices. Here, educators learn together, share and discuss the implementation of the new change and provide support as to ensure that the CCSS are impacting student learning in a purposeful way.

The institutionalization phase would provide ongoing support and follow through discussion about how teachers are implementing the CCSS. It provides a way to evaluate the new change in terms of teacher's level of use and concerns and how the change is impacting student learning.

Another way to support teachers' learning is to establish a learning community in 
schools. "Smaller groups appear to create more effective professional learning" (Goodwin, 2014, p. 81). The Florida Conference has a long-standing practice with providing the resources, time, and effort toward the establishment of professional learning communities. Through the use of study groups and workshops, the conference has supported its teachers through many educational initiatives. It is possible for the conference to do the same for the CCSS.

Recently, there has been a greater and more consistent and purposeful movement toward peer coaching support from the Conference where small teams are put together to learn and support each other. Using peer coaching study teams help to support the effort of staff development and provide the necessary support for teachers to implement new strategies successfully (Showers \& Joyce, 1996). However, this movement needs to be more organized with the time and schedule provided for peers to meet, plan, and collaborate together.

\section{Conclusions}

Because of this study, we now know that:

1. The Florida Conference teachers deemed the CCSS, along with the shifts in ELA and Mathematics important enough and worth the time, effort, passion it takes to learn about them and to use them effectively in the classroom.

2. Despite not having consistent and intentional training about the CCSS, participants in this study, held objective views in their evaluation of both the negative and positive impact of the CCSS.

3. Teachers in this study embraced the CCSS and did their best to implement them through their own research and study. 
4. There exists a culture of collaboration among the teachers that allows them to take ownership of the initial CCSS training and to continue with their own learning.

5. Teachers in this study perceived that generally the CCSS had a positive impact on their students.

\section{Implications for Practice}

1. Florida Conference should review their Professional Development plan for purposefulness and intentionality.

Educators in the study indicated a need for more Professional Development that is succinct, purposeful, and directly related to specific curriculum initiatives that they are responsible to implement.

Any school system such as the Florida Conference that spends the time, effort, and energy into professional learning should be guided by a vision, a set of goals.

2. Provide for a sufficient amount of time for learning to take place.

Educators in this study indicated the need for additional time in training. They would have liked to have more time to learn, practice, and prepare for the CCSS.

Successful change often takes a number of years.” (Sterrett, 2011, p. 51). According to Fullan (2014), it takes three to five years for something to become institutionalized. Teachers need the time to study and understand the CCSS and their accompanying principles then they need the proper resources to teach. For examples, the time allotted for the teachers to learn would consist of training regarding the CCSS but also the shifts such as for example, regular practice with complex texts and their academic language. They would learn what exactly is a complex text, what is the 
academic vocabulary and language that will form the "staircase of learning" from $\mathrm{K}-12$ and that will prepare our students for the world of college and work.

I am reminded of a reading workshop that I presented to a group of teachers. I discussed the ELA shifts and shared the definition of Close Reading. Many of the teachers seemed incredulous and others just sat there, not believing but wanting to because there was a trust between us. I caught the doubtful looks and paused to address it. "What's up?" I said. One of the teachers, looked around, smiled and spoke with a shrug: "It's just that, this is not the correct definition of close reading." She hastened further: "at least, not the way we know it." I gave her the time to continue in her explication and we finally came to the understanding that their definition of close reading involved the CLOZE reading strategy where students fill in the appropriate vocabulary in a sentence. I wrote both words on the board; defined, gave purpose, and examples for each. Teachers deserve the time necessary to grapple with ideas and to make meaningful connections that will support their learning and teaching.

3. Facilitate support for teachers throughout the process of change.

Educators in the Florida Conference indicated through their responses that they were introduced to CCSS in passing as they were being introduced to the new Mathematics curriculum.

"Change is a process. It is not an event" (Hall \& Hord, 2011, p. 8). The initiation of a new program is simply that: an initiation, a beginning. It does not nor can it end there. It needs time and training for the process of learning to happen. Teachers need the time to go through the process of initiation, implementation, and institutionalization. In the literature review, Fullan (2007) describes each part of the process and the necessity 
for teachers to initially understand the change and the purpose for it; to put the change into practice as part of the implementation process; and to mesh the fabric into the life of the organization through the institutionalization process.

In order for the process to be successful, there must be a single focus on that change and nothing else. Before, during, and a couple of years after the CCSS were adopted, the only learning that should have been taking place should have been related to the CCSS and their related components - the shifts and resources. However, there have been various different adoptions and initiatives since the inception of the CCSS. For example, currently we are working to adopt a new Bible curriculum-called Encounter that has its beginning in New Zealand. The curriculum is founded on best practices and student-centered learning so adopting it is not the concern. The real issue is that it has only been a year since the Florida Conference adopted a new social studies curriculum and less than three years for a new science curriculum and still, they are in the process of revising and upgrading the old reading curriculum, Pathways.

Teachers in the Florida Conference should have the time to go through the process of one change at a time and to receive all necessary and related trainings, materials, and resources that will make the change in the adoption of CCSS possible and relevant to both teachers and students.

Changes and initiatives begin and end with the classroom teacher (Hall \& Hord, 2011). The classroom is where all hope goes to die or live. It is important that the hope of the CCSS adoption be given the chance to live and thrive in order to make a viable impact on student learning.

4. Allot the resources necessary to implement the CCSS. 
Educators in the Florida Conference indicated that they were introduced to the Mathematics curriculum as part of the adoption of the CCSS. No curriculum or materials were obtained to facilitate the teaching of reading.

The Go Math! and the Big Ideas Mathematics programs were introduced in 2012 as part of the move for the conference to adopt the CCSS. At that time, our reading program had been in place a few years prior. While the Mathematics program changed to accompany the new CCSS, the reading program did not. Pathways had been a program that marked the shift in thinking from the old basal series to a more child-centered and strategies focus in teaching and learning reading. It was a good first step but not a complete literacy program as it did not, for example, address guided reading. It could not have addressed the shifts for the ELA standards as they were not related in time or in ideas. However, participants referred to Pathways in discussion of the CCSS because that's all they know.

The same process, of course, would go for Mathematics. Time, process, and resources are needed for teachers to be able to teach according to the shifts that the standards for Mathematics have brought forth to our educational lives. The adoption of the Mathematics curriculum is an important step but time and process are needed to bring it all together.

5. Adopt or merge, and utilize one set of standards.

Educators in the Florida Conference expressed confusion over the various standards that they must use in planning, teaching, and assessing in the classroom.

Throughout the study, the participants referred to several different standards. They mentioned the standards from the NAD, Adventist Edge, Pathways, and pacing 
guides. The CCSS provide a set of goals for ELA and Mathematics. These goals are sufficient to guide the teachers in their planning, teaching, and assessing. The Florida Conference educational leaders should align the curriculum with one set of standards. As an example, the NAD is in the process of revising and renewing the old Pathways curriculum, now is the right time to match the Pathways reading program to the CCSS and to have one set of standards by which teachers plan, instruct, and assess their teaching.

6. Establish a supportive evaluation system.

Educators from the Florida Conference indicated the need for support throughout the implementation of the CCSS. Proper follow-up about the use of the CCSS would have afforded the teachers the chance to ask for support and feedback.

Follow-up is an important part of Professional Development. There must be a formative evaluative system whereby teachers are evaluated for competence and to be provided appropriate feedback along with support and suggestions that will push them toward expert knowledge of the CCSS and the use of its related principles.

\section{Recommendations for Future Research}

This study was conducted with teachers from the Florida Conference. It sought to understand their perceptions regarding the adequacy of the Professional Development to support the implementation of the CCSS; how they are implementing the CCSS in the classroom in terms of planning, teaching, and assessing; and their perceptions regarding the impact of the CCSS on student learning.

One recommendation would be for a similar study to be conducted across conferences in the Southern Union and the NAD. This would perhaps give a larger 
picture and allow for more voices to join in to share their perceptions about the adoption of the CCSS.

A study that includes educators in both the public and private sectors to identify similarities and differences in experiences and perceptions regarding the CCSS.

Compare the Mathematics test scores of students based on the length of time they have been taught with the CCSS. Mathematics would have been appropriate since the move to adopt the new Mathematics curriculum was in relation to the adoption of the CCSS.

\section{Limitations of the Study}

There were limitations to this study that may have the potential to limit the findings or results. During the research, I analyzed each interview but did not use the emerging data to shape future data collection. While I contacted one participant for clarification, the purpose was not to collect additional data. Once collected, the data was analyzed and reported.

\section{Closing Thought}

The purpose of this study was first to examine the perceptions of teachers in regard to the adequacy of Professional Development to support the CCSS adoption by the Florida Conference. Second, I inquired how teachers were implementing the CCSS in their planning, teaching, and assessing. Finally, I sought to understand teachers' perceptions of the impact the CCSS were having on student learning.

This study has given a voice to the participants that can echo across the Florida Conference and to other teachers in other places. We now have an understanding about 
the perceptions, feelings, and beliefs of the teachers in regard to the CCSS. The study has shown that teachers in the Florida Conference are exposed to a variety of trainings but did not receive adequate training to support the implementation of the CCSS. While the trainings have varied, they needed to be more intentional and targeted to specific learning. It also shows that the participants, somewhat surprisingly did not object to the adoption of the CCSS. Moreover, the participants hold their students and their subjects in very high regards and think it a worthwhile endeavor to desire to continue to learn and grow. That is wonderful news. 
APPENDIX A

REQUEST FOR PERMISSION 


\section{Request for Permission to Do Research from Florida Conference}

Rose Thomas

674 Hermits Cove

Altamonte Springs, FL 32701

Rose.thomas@floridaconference.com

(407) 790-2084

June 23, 2016

Dear Florida Conference Education Department:

My name is Rose Thomas and I work for the Florida Conference as a Vice Principal assigned to the Forest Lake Education Center School for Grades Pre-K-8. I am conducting a qualitative case research study using the teachers within the conference. As a Ph.D. student at Andrews University School of Education and a leader in the Florida Conference, I am interested in finding out the perceptions of teachers regarding the Common Core state standards (CCSS) implementation in the Florida Conference of Seventh-day Adventist schools. The following questions will guide the study:

1. What are the teachers' perceptions regarding the adequacy of their Professional Development to support the implementation of the CCSS?

2. How are teachers implementing the CCSS in the classroom in terms of planning, teaching, and assessment?

3. What are teachers' perceptions regarding the impact of the CCSS on student learning?

Once I receive your permission, I will email a letter to the teachers who have been working in the conference since 2012 of the schools informing them that I've received consent from your office to conduct the study. I will randomly choose teachers from among those who have been working in the conference at the time of the CCSS adoption in 2012. The observations will be in schools that are within 50-mile radius of the Florida Conference headquarters. Specifically, those schools will include: Beryl Wisdom Adventist School, Daytona Beach Indigo Christian Junior Academy, Deltona Adventist School, Forest City Adventist School, Kissimmee Osceola Adventist Christian School, Mount Dora Gateway Christian School, and Orlando Junior Academy. Eight (8) educators will be selected from the various schools and out of them, three (3) will be chosen for observation and documents/artifacts analysis. The interview will be the first part of my investigation. For the second part, I will randomly choose teachers who volunteer for observation during the interviewing process. I will use a recorder or online medium for the interviews and journals and a camera for observation field notes and documents analysis.

Regarding confidentiality, the information gathered in the study will be handled with strict confidentiality. Each teacher will be assigned a code, and all information obtained from the teachers will be linked to the codes rather than to specific teachers' names. Recordings of 
teachers will also only be identified by codes. The list connecting each teacher's name to a code will be kept in a locked file, and when the study is completed and the data have been analyzed, this list will be kept for three years under lock and will subsequently be destroyed. Teachers' names will not be used on the report. All and any names used in the observation part of the literature review will be fictitious.

There is no risk associated with the study. Since this is a qualitative case study, based on the work we do as teachers and change implementers, analysis of the data and the results will serve as a tool to recommend improvements that will support our learning and teaching. Participating in the study will allow teachers to reflect on their perceptions about the CCSS adoption and to share their thoughts, ideas, and feelings. Teachers' participation in this survey will not affect their work status or work evaluation.

Please sign the attached consent form to allow me to proceed with the study using the teachers from the conference as the participants. Once the email goes out, I will wait for volunteers, if I get 8 participants, I will have my sample; if not, the process of random selection and emailing will continue until I do. The consent forms will be collected from participant. For your benefit, I am enclosing the directions for the letter of your permission that Andrews University requires for me to submit.

I thank for your consideration. If you have any concerns about the study, please contact me using the information above.

Sincerely,

Rose J. Thomas 
APPENDIX B

FLORIDA CONFERENCE PERMISSION TO CONDUCT RESEARCH 


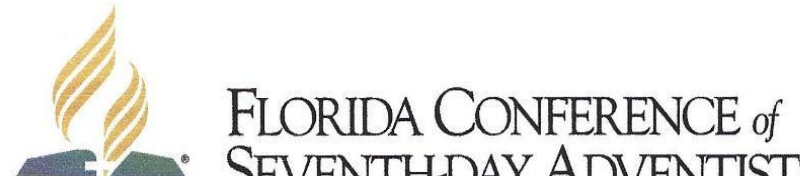

July 8, 2016

Institutional Review Board

Andrews University

4150 Administrative Drive, Room 322

Berrien Springs, MI 49104-0355

RE: Roseamana (Rose) Thomas

Dear Institutional Review Board,

The Office of Education of the Florida Conference of Seventh-day Adventists grants permission for Rose Thomas to conduct research with our educators for her study,

\section{A QUALITATIVE CASE STUDY OF THE IMPLEMENTATION OF THE COMMON CORE STATES STANDARDS IN THE FLORIDA CONFERENCE OF SDA SCHOOLS.}

Specifically, we grant permission for Rose to conduct interviews with educators, classroom observations, and collect teacher-supplied artifacts.

Please feel free to contact me should you have any questions.

Sincerely,

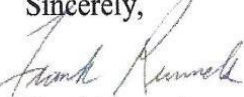

Frank Runnels

Vice President

Office of Education

bjm 
APPENDIX C

EMAIL TO FLORIDA CONFERENCE TEACHERS 


\section{EMAIL TO FLORIDA CONFERENCE TEACHERS}

August 2016-September 2016

Dear Colleagues of the Florida Conference,

I have been working on a doctoral degree in Curriculum and Instruction and I am at the research phase of my study. Please find enclosed a letter regarding my dissertation study. You have been selected to participate in this study because the records show that you have worked with the conference since the year 2012 when the CCSS were adopted. Your name was chosen at random from a list of two groups: $\mathrm{K}-5$ and 6-8 teachers. I am requesting your participation in this study. Please contact me as soon as possible with your response.

To be specific, I need elementary teachers and ELA and Mathematics middle school teachers to volunteer for my study. Once you volunteer, I will contact you to begin my research.

Thank you for your consideration!

Rose 
APPENDIX D

TEACHER CONSENT FORM 


\section{TEACHER CONSENT FORM}

Title of Study: A study to examine the perceptions of teachers regarding the implementation of the Common Core State Standards in the Florida Conference.

\section{Principal Investigator:}

Rose J. Thomas

Teaching, Learning, \& Curriculum Department

Andrews University School of Education

E-mail: rose.thomas@ @loridaconference.com

Phone: (407) 790-2084

\author{
Research Advisor \\ Larry D. Burton \\ Teaching, Learning, \& Curriculum Department \\ Andrews University School of Education \\ E-mail: burton@andrews.edu \\ Phone: (269) 519-8733
}

You are invited to participate in a research project. Your participation is necessary for the success of the study. However, it is entirely voluntary and you may choose not to participate. If you choose to participate, or if you withdraw your consent and stop your participation at any point in the study, your decision will have no impact on our personal or professional relationships or your professional status in the Florida Conference.

Although, you will not be paid for your participation, this study will give you a voice in the discussion of teaching and learning policies and practices in the Florida Conference. The study will allow you to reflect on your perceptions about the implementation of the Common Core adoption. Additionally, the results can inform and provide recommendations to our educational leaders as they enact changes in the schools.

All research participants will be asked to sit for an interview. Interviews will be recorded to ensure I accurately capture your experiences, ideas, and thoughts. You may choose not to be recorded. In that case, I will take notes during our interview to capture your thoughts. Each teacher will be assigned a code and all information obtained from the teachers will be linked to the code rather than to specific teachers' names. Use of code names will ensure I am able to keep your information strictly confidential. I will be the only person who knows the names of the teachers who participate is this study. My dissertation committee members will only see the codes for each participant.

Teachers will be chosen from those who have worked in the conference since the year 2012 when the Common Core State Standards were adopted. The observation will be done in schools that are located within 50-mile radius of the Florida Conference headquarters for ease of access and speed of collecting the data. Specifically, those schools will include: Beryl Wisdom Adventist School, Daytona Beach Indigo Christian Junior Academy, Deltona Adventist School, Forest City Adventist School, Kissimmee Osceola Adventist Christian School, Mount Dora Gateway Christian School, and Orlando Junior Academy.

If you have any questions about the study, please contact me or my research advisor, Dr. Burton.

\section{SIGNATURES:}

You are making a decision to participate in this study. Your signature below indicates that you have read the information provided above and have decided to participate in the study. You are free to withdraw consent to participate in this study at any time by contacting the Principal Investigator, Rose Thomas. You will be given a copy of this consent form for your records.

Printed Name of Teacher

Signature of Teacher Date




\section{REFERENCE LIST}

Alberti, S. (2012). Making the shifts. Educational Leadership, 70(6), 42-46.

Barth, R. S. (2002). The culture builder. Educational Leadership, 59(8), 6-11.

Berkowicz, J., \& Myers, A. (2013, September 10). Successful leaders will find a way. Education Week: Leadership 360. Retrieved from Blogs.edweek.org/edweek.

Birman, B. F., Desimone, L., Porter, A. C., \& Garet, M. S. (2000). Designing professional development that works. Educational Leadership, 57(8), 28-33.

Betts, F. (1992). How systems thinking applies to education. Educational Leadership, $50(3), 38-41$.

Blosveren, K., Liben, M., \& DeWitt, S. (2014). Common core: The challenge and the opportunity. Retrieved from actonline.org

Bond, J. B. (2011). Professional development: Five musts for turnaround schools. ASCD Express, 6(12).

Brooks, J., \& Dietz, M. (2012-2013). The dangers and opportunities of the common core. Educational Leadership, 70(4), 64-67.

Burns, M. (2012, December-2013, January). Go figure: Math and the common core. Educational Leadership, 70(4), 42-46.

Center for Public Education. (2013, October). Understanding the common core standards - what they are-what they are not. Retrieved from centerforpubliceducation.org/commoncore

Charmaz, K. (2014). Constructing grounded theory (2nd ed.). Thousand Oaks, CA: Sage.

Common Core State Standards Initiative. (2017). Preparing America's students for success. Retrieved from corestandards.org

Conley, D. (2011). Building on the common core. Educational Leadership, 68(6), 16-20.

Creswell, J. W. (2014). Research design: Qualitative, quantitative, and mixed methods approaches (4th ed.). Thousand Oaks, CA: Sage. 
Culham, R. (2014). The writing thief: Using mentor texts to teach the craft of writing. Newark, DE: International Reading Association.

Davies, A. (2014). Consider the core: Why independent schools shouldn't ignore the common core state standards. Independent Journal, 73(2).

Dewey, J. (1916). Democracy and education. New York, NY: Free Press.

Dufour, R. (2002). The learning centered principal. Educational Leadership, 59(8), 1215.

Dufour, R. (2004). What is a professional learning community? Educational Leadership, 61(8), 6-11.

Dufour, R. (2014). Harnessing the power of PLCs. Educational Leadership, 71(8), 3035.

Edwards, H. S., \& Springs, H. (2014). Core crash. New education standards have turned back-to-school into a battlefield. Time, 187(7), 40-41.

Eilers, L. H., \& D'Amico, M. (2012). Essential leadership elements in implementing common core state standards. Delta Kappa Gamma Bulletin, 78(4), 46-50.

Exstrom, M., \& Thatcher, D. (2014, September). Common core: Put to the test. State Legislatures Magazine, 22-5, 7.

Farmer, B. (2014, June 23). Common core is rotten to the core. New American. Retrieved from thenewamerican.com/culture/education/item/18437-common-core-is-rottento-the-core

Finn Jr., C. E., \& Brickman, M. (2014). Beyond the common core. National Review, 46(14), 21-22.

Fisher, D., \& Frey, N. (2012). How to create a culture of achievement in your school. Alexandria, VA: ASCD.

Freire, P. (2011). Pedagogy of the oppressed. New York, NY: Continuum International.

Frontier, T., \& Mielke, P. (2016). Making teachers better not bitter: Balancing evaluation, supervision, and reflection for personal growth. Alexandria, VA: ASCD.

Fullan, M. (1993). Why teachers must become change agents. Educational Leadership, $50(6), 12-17$.

Fullan, M. (2002). The change leader. Educational Leadership, 59(8), 16-21. 
Fullan, M. (2007). The new meaning of educational change (4th ed.). New York, NY: Teachers College Press.

Fullan, M. (2014). The principal: Three keys to maximize impact. San Francisco, CA: Jossey-Bass.

Gardner, N., \& Powell, R. (2013). The common core is a change for the better. Kappan, 95(4), 49-53.

Glaser, B. G., \& Strauss, A. L. (2006). The discovery of grounded theory: Strategies for qualitative research. New Brunswick, Canada: Aldine Transaction.

Goodwin, B. (2014). Research says: Keep professional learning groups small, but connected. Educational Leadership, 71(8), 80-82.

Goodwin, B., \& Miller, K. (2012). Feedback for learning: Research says good feedback is targeted, specific, and timely. Educational Leadership, 70(1), 82-83.

Greene, K. (2012). Common core: Fact vs. fiction. Scholastic Instructor, 122(2), 26-27.

Griffith, D. (2015). Catching up with the common core. Educational Leadership, 68(6), 95.

Gruenert, S. (2005). Correlations of collaborative school cultures with student achievement. National Association of Secondary School Principals, 89(645), 4355.

Gruenert, S., \& Whitaker, T. (2015). School culture rewired: How to define, assess and transform it. Alexandria, VA: ASCD.

Gulamhussein, A. (2013). Teaching the teachers: Effective professional development in an era of high stakes accountability. Washington, DC: Center for Public Education. Retrieved from centerforpubliceducation.org/Main-Menu /Staffingstudents/Teaching-the-Teachers-Effective-Professional-Development-inan-Era-of-High-Stakes-Accountability/Teaching-the-Teachers-Full-Report.pdf

Guskey, T. (2000). Evaluating professional development. Thousand Oaks, CA: Corwin.

Guskey, T. (2002). Does it make a difference? Evaluating professional development. Educational Leadership, 59(6), 45-51.

Guskey, T. (2014). Planning professional learning. Educational Leadership, 71(8), 1016.

Hall, A. (2014). Moving beyond the noise of the common core. Reading Today, 32(3), $18-21$. 
Hall, G., \& Hord, S. (2011). Implementing change: Patterns, principles, and potholes (3rd ed.). Upper Saddle River, NJ: Pearson Education.

Hargreaves, A., \& Fink, D. (2004). The seven principles of sustainable leadership. Educational Leadership, 61(7), 8-13.

Hess, F. (2014, Fall). How the common core went wrong. National Affairs, 32, 3-19. Retrieved from nationalaffairs.com/publications/detail/how-the-common-corewent-wrong

Hess, F., \& McShane, M. (2013). Common core in the real world. Kappan, 95(1), 9-25.

Holloway, J. H. (2003). Research link/linking professional development to student learning. Educational Leadership, 61(3), 85-87.

Hooks, B. (1994). Teaching to transgress: Education as the practice of freedom. New York, NY: Routledge.

Jacobs, H. (2010). Curriculum 21: Essential education for a changing world. Alexandria, VA: ASCD.

Joyce, B., \& Showers, B. (2002). Student achievement through staff development (3rd ed.). Alexandria, VA: ASCD.

Lattimer, H., McBride, M., \& Combs, D. (2010). Learning from the other generation. Educational Leadership, 67(8). Retrieved from ascd.org/publications/educational -leadership/may10/vol67/num08/Learning-from-the-Other-Generation.aspx

Little, J. W. (2009). Teacher's work: Individuals, colleagues, and contexts. New York, NY: Teachers College Press.

MacGilchrist, B. (1996). In the United Kingdom/linking staff development with children's learning. Educational Leadership, 53(8), 72-75.

Maunsell, P. (2014). Communication is key to common core. Kappan, 95(6), 61-65.

McTighe, J., \& Thomas, R. S. (2003). Backward design for forward action. Educational Leadership, 60(5), 52-55.

McTighe, J., \& Wiggins, G. (2004). Understanding by design: Professional development workbook. Alexandria, VA: ASCD.

Meier, D., Finn Jr., C. E., \& Schlechty, P. (2010). Are national standards the right move? Educational Leadership, 67(7). 26.

Merriam, S. B., \& Tisdell, E. J. (2016). Qualitative research: A guide to design and implementation (4th ed.). San Francisco, CA: Jossey-Bass. 
Miles, M. B., Huberman, A. M., \& Saldaña, J. (2014). Qualitative data analysis: A methods sourcebook (3rd ed.). Thousand Oaks, CA: Sage.

Munson, L. (2011). What students really need to learn. Educational Leadership, 68(6), $10-14$.

Murphy, C. (1992). Study groups foster schoolwide learning. Educational Leadership, 50(3), 71-74.

Murphy, C. (1995). Whole faculty study groups. Retrieved from murphyswfsg.org /index.htm

National Governors Association Center for Best Practices \& Council of Chief State School Officers. (2010). Common core state standards: Preparing America's students for success. Washington, DC: Author.

Newman, S., \& Roskos, K. (2013). Why common core matters. Reading teacher, 67(1), 9-11.

Obama, B. (2009, July 24). Remarks at the Department of Education. Administration of Barack Obama, 2009, 1167-1168.

Ohler, J. (2013, February). The uncommon core. Educational Leadership, 70(6). 42-46.

O’Neill, J. (2000). Fads \& fireflies: The difficulties of sustaining change. Educational Leadership, 57(7), 6-9.

Ornstein, A. C., Pajak, E. F., \& Ornstein, S. B (2011). Contemporary issues in curriculum (6th ed.). Boston, MA: Pearson Education.

Patton, M. Q. (2002). Qualitative research \& evaluation methods (3rd ed.). Thousand Oaks, CA: Sage Publications, Inc.

Patton, M. Q. (2015). Qualitative research \& evaluation methods (4th ed.). Thousand Oaks, CA: Sage.

Perkins, D., \& Reese, J. (2014). Special topic: When change has legs. Educational Leadership, 71(8), 42-47.

Reeves, D. B. (2007-2008). Leading to change: Making strategic planning work. Educational Leadership, 65(4), 86-87.

Rotherham, A. J., \& Willingham, D. (2009). 21st century skills: The challenge ahead. Educational Leadership, 67(1), 16-21.

Rothman, R. (2012a). A common core of readiness. Educational Leadership, 69(7), 1015.

Rothman, R. (2012b). Laying a common foundation for success. Kappan, 49(3), 57-61. 
Rubinstein, G. (2013, Summer). How to survive education reform without losing your job, your ideals, or your mind. Educational Leadership, 70, 84-86.

Rust, T. (2012). Technology and engineering education and the common core standards. Technology \& Engineering Teacher, 72(3), 32-36.

Saldaña, J. (2016). The coding manual for qualitative researchers. Thousand Oaks, CA: Sage.

Sawchuk, S. (2012). Many teachers not ready for the common core. Education Digest, $78(2), 16-22$.

Schaffhauser, D. (2014). 9 ways to help parents understand the common core. Technology Horizons in Education. Retrieved from thejournal.com/articles/2014 /08/12/9-ideas-to-help-explain-common-core-to-parents.aspx

Scherer, M. (2014). Perspectives: Bright spots in professional learning. Educational Leadership, 71(8), 7.

Schwahn, C., \& Spady, W. (1998). Why change doesn't happen and how to make sure it does. Educational Leadership, 56(7), 45-47.

Shannahan, T. (2012). The common core ate my baby and other urban legends. Educational Leadership, 70(4), 10-16.

Shannahan, T. (2013). You want me to read what? Educational Leadership, 71(3), 10-15.

Shannahan, T., \& Shannahan, C. (2017). Disciplinary literacy: Just the FAQs. Educational Leadership, 74(5),18-22).

Showers, B., \& Joyce, B. (1996). The evolution of peer coaching. Educational Leadership, 53(8), 12-16.

Sire, J. (2009). The universe next door (5th ed.). Downers Grove, IL: Intervarsity Press.

Smith, J., Flowers. P., \& Larkin, M. (2009). Interpretative phenomenological analysis theory, method, and research. Thousand Oaks, CA: SAGE.

Sterrett, W. (2011). Insights into action: Successful school leaders share what works. Alexandria, VA: ASCD.

Svinicky, M. (2004). Learning and motivation in the postsecondary classroom. Bolton, MA: Anker.

Tepe, L. (2014). Common core goes to college: Building better connections between high school and higher education. Washington, DC: New America. 
Thomas, R. (2013, Spring). Personal professional synthesis. Unpublished manuscript for the class Philosophical Foundations for Professionals. Andrews University: Berrien Springs, MI.

Tomlinson, C. A. (1999). The differentiated classroom: Responding to the needs of all learners. Alexandria, VA: ASCD.

Tomlinson, C. A. (2014). The differentiated classroom: Responding to the needs of all learners (2nd ed.). Alexandria, VA: ASCD.

Wallender, J. (2014). The common core state standards in American public education: Historical underpinnings and justifications. Delta Kappa Gamma Bulletin, 80(4), 7-11.

White, E. (2003). Education. Coldwater, MI: Remnant. (Original work published 1903)

Wickstrom, G. \& Bendix, T. (2000). "The Hawthorne effect:" What did the original studies actually show? Scandinavian Journal of Work, Environment, \& Health, 26(4), 363-367.

Wiggins, G. (2012). Feedback for learning: Seven keys to effective feedback. Educational Leadership, 70(1), 10-16.

Wiggins, G., \& McTighe, J. (2006). Understanding by design (2nd ed.). Upper Saddle River, NJ: Pearson Education.

Willis, S. (2002). Creating a knowledge base for teaching: A conversation with James Stigler. Educational Leadership, 69(6), 6-11.

Yatvin, J. (2013). Warning: The common core standards may be harmful to children. Kappan, 94(6), 42-44.

Zull, J. E. (2002). The art of changing the brain. Sterling, VA: Stylus. 
VITA 
Rose J. Thomas

rose.thomas@floridaconference.com

407-790-2084

\section{EDUCATION}

Andrews Adventist University

PhD Curriculum \& Instruction

2017

University of South Florida

MA Elementary Education

2000

University of South Florida

BA Communication Disorders

1994

\section{PROFESSIONAL EXPERIENCE}

Forest Lake Education Center, Longwood, FL

Vice Principal \& Curriculum Chair

2009-Present

- $\quad$ Supervise \& manage curriculum needs of 37 teachers and 600 PreK-8 students

- Manage \& operate the activities \& funds for Professional Development

- Initiate, develop, \& manage partnership between Seminole County and FLEC in the sharing of Title I \& II funds

- $\quad$ Supervise and evaluate Exceptional Student Services (ESS)

- Established program for gifted and talented students

- $\quad$ Created Faculty Leadership Team (FLT) to foster communication and leadership

Florida Conference - Oakwood University \& Southern University

2008-2015

Teacher Trainer

- Created and developed Summer Reading and Writing Clinics

- Mentored and coached teachers in the conference

Forest Lake Education Center, Longwood, FL

2006-2008

Elementary Teacher

- Taught first, second, and third grade classes

Winter Springs Elementary - Seminole County Schools, FL

2005-2006

Elementary Teacher

- Taught first grade classes

Baypoint Elementary - Pinellas County Schools, FL

2000-2005

Elementary Teacher

- Taught first grade classes

- Received Outstanding Educator Award

Northwest Elementary - Pinellas County Schools, FL

1994-1996

Speech \& Language Teacher

- Taught K-5 students with speech and language impairment

MEMBERSHIPS

Association for the Supervision of Curriculum Development International Reading Association 